\title{
Changes in storm tracks and energy transports in a warmer climate simulated by the GFDL CM2.1 model
}

\author{
Yutian Wu $\cdot$ Mingfang Ting $\cdot$ Richard Seager • \\ Huei-Ping Huang $\cdot$ Mark A. Cane
}

Received: 12 November 2009/ Accepted: 22 February 2010

(C) Springer-Verlag 2010

\begin{abstract}
Storm tracks play a major role in regulating the precipitation and hydrological cycle in midlatitudes. The changes in the location and amplitude of the storm tracks in response to global warming will have significant impacts on the poleward transport of heat, momentum and moisture and on the hydrological cycle. Recent studies have indicated a poleward shift of the storm tracks and the midlatitude precipitation zone in the warming world that will lead to subtropical drying and higher latitude moistening. This study agrees with this key feature for not only the annual mean but also different seasons and for the zonal mean as well as horizontal structures based on the analysis of Geophysical Fluid Dynamics Laboratory (GFDL) CM2.1 model simulations. Further analyses show that the meridional sensible and latent heat fluxes associated with the storm tracks shift poleward and intensify in both boreal summer and winter in the late twenty-first century (years 2081-2100) relative to the latter half of the twentieth century (years 1961-2000). The maximum dry Eady growth rate is examined to determine the effect of global warming on the time mean state and associated available potential energy for transient growth. The trend in maximum Eady growth rate is generally consistent with the
\end{abstract}

Y. Wu $(\bowtie)$

Department of Applied Physics and Applied Mathematics, Columbia University, New York, NY, USA

e-mail: yw2225@columbia.edu

M. Ting $\cdot$ R. Seager $\cdot$ M. A. Cane

Lamont-Doherty Earth Observatory, Columbia University, Palisades, NY, USA

H.-P. Huang

Department of Mechanical and Aerospace Engineering, Arizona State University, Tempe, AZ, USA poleward shift and intensification of the storm tracks in the middle latitudes of both hemispheres in both seasons. However, in the lower troposphere in northern winter, increased meridional eddy transfer within the storm tracks is more associated with increased eddy velocity, stronger correlation between eddy velocity and eddy moist static energy, and longer eddy length scale. The changing characteristics of baroclinic instability are, therefore, needed to explain the storm track response as climate warms. Diagnosis of the latitude-by-latitude energy budget for the current and future climate demonstrates how the coupling between radiative and surface heat fluxes and eddy heat and moisture transport influences the midlatitude storm track response to global warming. Through radiative forcing by increased atmospheric carbon dioxide and water vapor, more energy is gained within the tropics and subtropics, while in the middle and high latitudes energy is reduced through increased outgoing terrestrial radiation in the Northern Hemisphere and increased ocean heat uptake in the Southern Hemisphere. This enhanced energy imbalance in the future climate requires larger atmospheric energy transports in the midlatitudes which are partially accomplished by intensified storm tracks. Finally a sequence of cause and effect for the storm track response in the warming world is proposed that combines energy budget constraints with baroclinic instability theory.

Keywords Storm tracks · Global warming

\section{Introduction}

Mid-latitude storm tracks play an important role in the Earth's climate system. Eddies within the storm tracks transport large amounts of energy poleward affecting the 
mean climate while much climate variability on seasonal to decadal timescales is associated with changes in the storm tracks. Previous studies have contributed greatly to our understanding of the dynamics of the storm tracks in the present climate (see a review by Chang et al. (2002)). It is expected that the storm tracks will change as a consequence of greenhouse warming. Yin (2005) found that the zonal mean storm tracks tend to intensify and to shift poleward and upward in climate projections from the Intergovernmental Panel on Climate Change (IPCC) Fourth Assessment Report (AR4) for the late twenty-first century. However, the physical mechanism underlying such a shift is not well understood. Recent studies using Reanalyses for the latter half of the twentieth century (e.g., McCabe et al. (2001); Fyfe (2003)) or general circulation models (GCMs) forced with increased greenhouse gases (e.g., Lambert (1995); Geng and Sugi (2003); Lambert and Fyfe (2006); Gastineau and Soden (2009)) indicate an increase in intensity of extratropical cyclones and a decrease in frequency. Hall et al. (1994) found northward shifted and downstream intensified storm tracks in a high-resolution GCM with doubled carbon dioxide. However, some models (e.g., Stephenson and Held (1993); Bengtsson et al. (2006); Frierson et al. (2006); O'Gorman and Schneider (2008)) found a weakening or insignificant intensification of midlatitude transient eddies in the warming world.

The disagreement among models and analyses indicates the complex dynamics of the storm track response to increased greenhouse gases (Held (1993)). First of all, the conversion of available potential energy in the atmosphere supplies the energy for the growth of transient eddies according to linear baroclinic instability theory. The linear baroclinic instability growth rate is affected by both static stability and meridional temperature gradients in the atmosphere. In a warmer climate, temperature gradients near the surface in northern winter are expected to weaken ${ }^{1}$ due to strong high latitude warming whereas those in the upper troposphere strengthen (e.g., Meehl et al. (2007)). Consequently, the resulting baroclinicity tends to weaken in the lower troposphere but strengthen in the upper troposphere. It is unclear in the real atmosphere which of the two opposing changes dominates the storm activity although linear instability theory and numerical experiments suggest that the lower-tropospheric baroclinicity has a stronger influence on mid-latitude eddy activity (e.g., Held and O'Brien (1992); Pavan (1995); Lunkeit et al. (1998)). However, the reduced lower-tropospheric baroclinicity in northern winter is not consistent with increased eddy kinetic energy in previous studies (Yin (2005); Hall

\footnotetext{
${ }^{1}$ The projected surface warming has a local minimum in the North Atlantic region due to the weakening of the Atlantic Meridional Overturning Circulation (MOC) predicted by climate models.
}

et al. (1994)). Second, previous studies have noted the strong influence of atmospheric moisture on the midlatitude dynamics and eddy energy fluxes (Emanuel et al. (1987); Lapeyre and Held (2004); Frierson et al. (2007)), which can occur in varying ways (e.g., Held (1993); Pavan et al. (1999)). For example, increased latent heat release in the warm sector of rising air in the storm system can provide a source of available potential energy leading to more intense storms (Emanuel et al. (1987); Held (1993)); on the other hand, less intense and less frequent storms can be expected as the eddies in moist air are more efficient in transferring energy poleward (Held (1993)). However, Lorenz and DeWeaver (2007) suggested that the midlatitude circulation response to global warming is caused by the rising tropopause height rather than increased atmospheric moisture content and changes in low-level baroclinicity.

The poleward energy transport in the midlatitudes is dominated by the atmospheric component which contains a significant contribution from the midlatitude storm tracks (Trenberth and Caron (2001); Trenberth and Stepaniak (2003)). It is expected that changes in storm track locations and amplitudes can be related to changes in global planetary (atmospheric plus oceanic) and atmospheric energy balance and energy transports. This allows a further exploration of the dynamics underlying the storm track response as climate warms by connecting the midlatitude storm systems with the planetary energy balance. Hall et al. (1994) found that the zonal mean poleward energy transport by transient eddies, particularly the contribution from transient moisture flux, increases with doubled carbon dioxide by using the UK Meteorological Office GCM with a mixed-layer slab ocean model. However, they did not explore the links to radiative and nonradiative energy fluxes in the atmosphere.

In this study, we use the Geophysical Fluid Dynamics Laboratory (GFDL) CM2.1 model simulations to analyze the changes in the location and intensity of the storm tracks in twentieth and twenty-first centuries. Focusing on one single model allows an indepth analysis of the phenomenon. Ultimately this work should be repeated with other models. The GFDL CM2.1 global coupled climate model has been widely used to study a variety of phenomena both in the atmosphere and the ocean and for global anthropogenic climate change projections (e.g., Meehl et al. (2007); Yin (2005); Russell et al. (2006b); Held and Soden (2006); Lu et al. (2007); Seager et al. (2007)). Furthermore, this model is able to simulate not only the climatological storm track state (shown in Sect. 3) but also the seasonal and interannual variabilities (Delworth et al. (2006)). The future storm track projections are also broadly consistent with those previously identified Yin (2005). Yin (2005) pointed out the consistent poleward and upward shift and intensification 
of the midlatitude storm tracks in 15 coupled IPCC AR4 GCMs. These features are accompanied by the enhanced warming in the tropical upper troposphere and the associated change in midlatitude baroclinicity, as well as the poleward shifts in surface wind stress and precipitation.

A brief description of the data and methods is given in Sect. 2. Section 3 presents the storm track climatology as well as the storm track response to warming in both summer and winter. The relevance of the changes in baroclinic eddy energy transports to the changes in baroclinic instability and the time mean states is give in Sect. 4, followed by the change in atmospheric and planetary energy budget in Sect. 5. Conclusions and discussions are presented in Sect. 6 .

\section{Data and methods}

The model output analyzed in this paper is from GFDL's CM2.1 global coupled climate model developed at the GFDL of the National Oceanic and Atmospheric Administration (NOAA) in 2004 (Delworth et al. (2006)). The resolution of the land (LM2.1) and the atmospheric (AM2.1) components is $2^{\circ}$ latitude $\times 2.5^{\circ}$ longitude with 24 vertical levels in the atmosphere structured in a hybrid coordinate. The dynamical core of AM2.1 uses the finite volume method from Lin (2004). This model has been used prominently for climate change experiments in the Intergovernmental Panel on Climate Change Fourth Assessment Report (IPCC AR4) and the US Climate Change Science Program (US CCSP) reports. In a doubling $\mathrm{CO}_{2}$ concentration scenario (A1B scenario), this model has a climate sensitivity of $3.4 \mathrm{~K}$ in the global mean. ${ }^{2}$ In addition we use the daily data from the National Centers for Environmental Prediction-National Center for Atmospheric Research (NCEP-NCAR) reanalysis (Kalnay et al. (1996)) to validate the current climate transient eddy activity in the GFDL CM2.1 global climate model.

We use both the twentieth and the twenty-first century simulations in this study. For the twenty-first century simulation, we use the daily data from the A1B scenario. To identify the climate change response, we compare the time mean of the late twenty-first century (years 20812100) with that of the latter half of the twentieth century

\footnotetext{
${ }^{2}$ The GFDL CM2.1 model included both stratospheric ozone depletion in the twentieth century simulation and ozone recovery in the A1B scenario simulation. Son et al. $(2008,2009)$ found that the recent poleward shift of the midlatitude westerly jet and the poleward expansion of the Hadley Cell in the Southern Hemisphere were partially forced by ozone depletion and will be likely to be weakened or even reversed (depending on models) by anticipated ozone recovery in the current century. Ozone change and its effect are almost negligible in the Northern Hemisphere.
}

(years 1961-2000) and define the trend of climate change as the difference between the two periods. A 21-point standard band-pass filter is applied to daily data to retain the variability on synoptic time scales of 2-8 days (Blackmon (1976)). All transient eddy statistics computed in this study are based on band-pass filtered data.

\section{Poleward shift and intensification of the storm tracks}

The storm track activities in this study are represented by several major transient eddy statistics (band-pass filtered) including the transient momentum flux $\left(\overline{u^{\prime} v^{\prime}}\right)$ and the variance of eddy meridional velocity $\left(\overline{v^{\prime} v^{\prime}}\right)$ at $250 \mathrm{mb}$, the meridional sensible heat flux $\left(\overline{v^{\prime} T^{\prime}}\right)$ and moisture flux $\left(\overline{v^{\prime} q^{\prime}}\right)$ at $700 \mathrm{mb}$.

We first compare the transient eddy statistics in the current climate simulations of the GFDL CM2.1 model to that in the NCEP-NCAR reanalysis. Figure 1 shows the climatology of $\overline{v^{\prime} v^{\prime}}$ at $250 \mathrm{mb}$ and the zonal mean $\left[\overline{v^{\prime} v^{\prime}}\right]$ (the square bracket denotes zonal average) as a function of latitude and pressure levels in December-February (DJF) averaged over the years 1961-2000 from the NCEP-NCAR reanalysis and the GFDL CM2.1 model simulation. The locations of the Pacific and Atlantic storm tracks are well simulated as well as those in the Southern Hemisphere (SH). But the North Atlantic storm track simulated in the model is more zonally oriented than that in observations. The Northern Hemisphere (NH) storm tracks are weaker in the GFDL CM2.1 model than in observations while the magnitude of the SH storm tracks is well simulated. Similar results are found comparing other eddy statistics between the model simulation and reanalysis in both DJF and June-August (JJA) (not shown).

\subsection{Horizontal structures}

Figure 2 shows the twenty-first century trend in horizontal structures of various eddy statistics in DJF and JJA (colors) along with the twentieth century climatology (black contours). The predominant features are the poleward and eastward (downstream) intensifications of the storm activity accompanied by a weak equatorward reduction for both the North Pacific and North Atlantic storm tracks. These lead to a slight poleward shift and a large poleward and eastward expansion of the storm tracks in the late twenty-first century. The response of the North Atlantic storm tracks is much stronger than that of the North Pacific one in both seasons. Take $\overline{v^{\prime} T^{\prime}}$ at $700 \mathrm{mb}$ as an example: there is an approximately $2^{\circ}$ poleward shift and $20-30 \%$ increase in maximum intensity in northern winter (Fig. 2e). At the entrance regions of the two storm tracks, i.e. off the eastern coasts of Asia and North America, there is a weakening of 
Fig. 1 Comparison of bandpass filtered variance of meridional velocity, $\overline{v^{\prime} v^{\prime}}$ produced in the GFDL CM2.1 model simulations (right column) with that derived in the NCEP-NCAR reanalysis (left column). a Shows the climatology of $\overline{v^{\prime} v^{\prime}}$ at $250 \mathrm{mb}$ and $\mathbf{c}$ shows the zonal mean $\left[\overline{v^{\prime} v^{\prime}}\right]$ as a function of latitude and pressure $(\mathrm{mb})$ in December-February (DJF) during the years 1961-2000 from the NCEP-NCAR reanalysis. $\mathbf{b}$ and $\mathbf{d}$ Are the counterparts from the model simulations. Contour intervals are $20 \mathrm{~m}^{2} / \mathrm{s}^{2}$. An 8-day bandpass filter has been applied to produce the variability of 2-8 days (a) DJF vhuh 250mb 1961-2000 NCEP

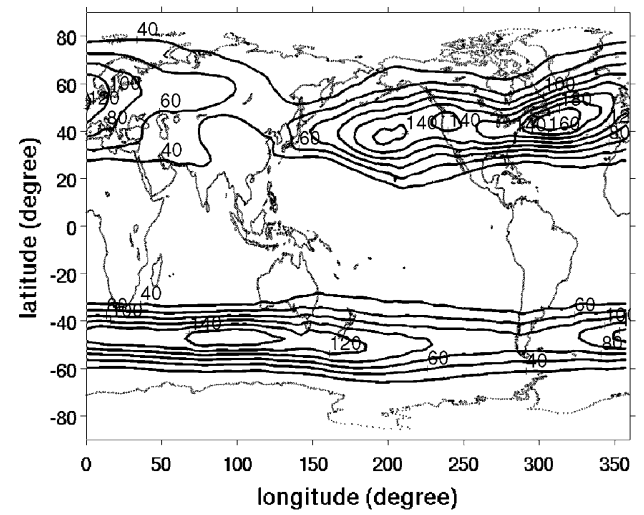

(c) DJF vhvh 1961-2000 NCEP

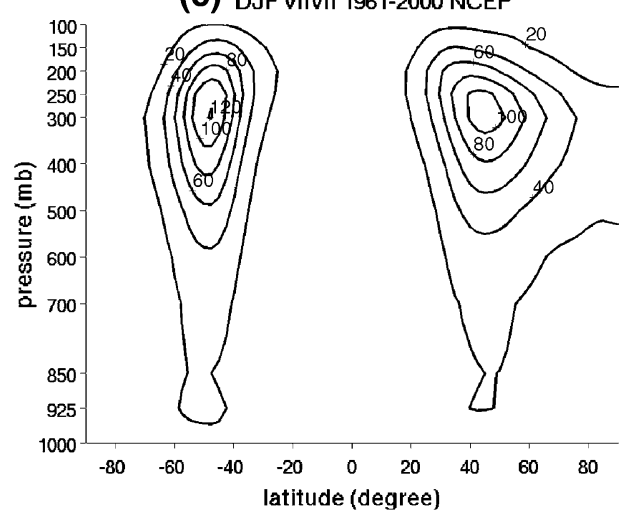

(b) DJF vhvh 250mb 1961-2000 Gr UL CM2.1

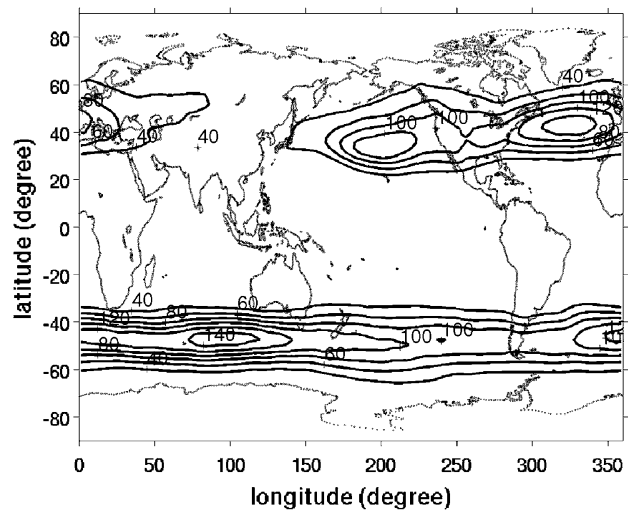

(d) DJF vhvh 1961-2000 GFDL CM2.1

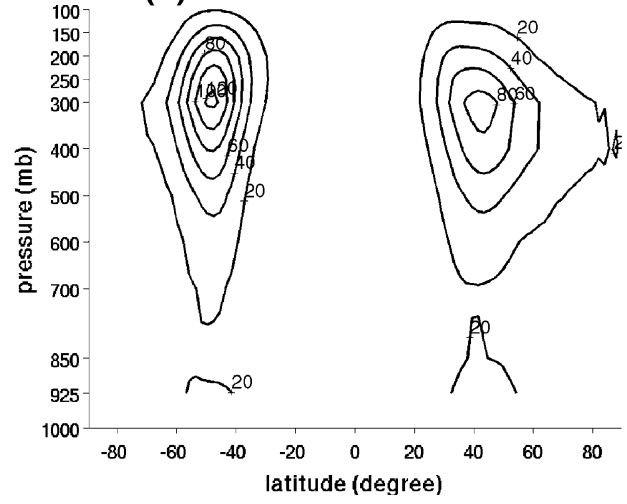

the transient meridional sensible heat flux due to reduction in land-sea temperature contrast and resulting reduction in surface upward sensible heat flux from the ocean, while the magnitude increases significantly in the downstream and exit regions stretching northeastward to the west coast of North America and into Western Europe (Fig. 2e). The transient moisture flux $\overline{v^{\prime} q^{\prime}}$ also intensifies in both seasons in the two storm track regions (Fig. $2 \mathrm{~g}$, h). These changes in eddy activity largely agree with Hall et al. (1994). In the Southern Hemisphere, the intensification on the poleward flank of the storm track regions is significant and zonally symmetric in both seasons.

\subsection{Zonal mean structures}

The zonal mean eddy statistics are shown in Fig. 3 with the twentieth century climatology in contours and the twentyfirst century changes in colors. The consistent poleward shift and intensification on the poleward flank of all the eddy statistics can be seen in both seasons in both hemispheres. In some eddy statistics, there is an upward shift as well. Furthermore, the increased meridional moisture transport in the future climate is consistent with the poleward shift and intensification of the midlatitude precipitation zone and the resulting poleward expansion and drying of the subtropical dry zones (e.g., Seager et al. (2007)). It is worth noting that the trend in zonal mean meridional heat transport in southern winter (JJA) is a local intensification rather than a poleward intensification and expansion (Fig. 3f).

\section{Relating changes in baroclinic eddy energy transports to changes in instability and the mean state}

The maximum intensity in synoptic eddy activity in the midlatitudes has long been related to the existence of strong baroclinic zones and the associated baroclinic instability which converts available potential energy of the time mean flow to eddy kinetic energy (e.g., Lorenz (1955); Eady (1949); Charney (1947)). One of the measures of linear baroclinic instability is the maximum Eady growth rate, which has been mathematically simplified and shown to be a useful estimate of the growth rate of the most rapidly growing instability in a range of baroclinic instability problems (Lindzen and Farrell (1980)). Hoskins and Valdes (1990) used the parameter to quantify the geographical location and intensity of the storm tracks. 
Fig. 2 Global warming trends in $\mathbf{a}$ and $\mathbf{b} \overline{u^{\prime} v^{\prime}}$ at $250 \mathrm{mb}$, $\mathbf{c}$ and $\mathbf{d} \overline{v^{\prime} v^{\prime}}$ at $250 \mathrm{mb}$, e and $\mathbf{f} \overline{v^{\prime} T^{\prime}}$ at $700 \mathrm{mb}$ and $\mathbf{g}$ and $\mathbf{h} \overline{v^{\prime} q^{\prime}}$ at $700 \mathrm{mb}$, in DJF and JJA, respectively, from the GFDL CM2.1 model simulations, plotted in colors, with the twentieth century climatology in contours. Contour intervals are $5 \mathrm{~m}^{2} / \mathrm{s}^{2}$ for $\mathbf{a}$ and $\mathbf{b}, 20 \mathrm{~m}^{2} / \mathrm{s}^{2}$ for c and $\mathbf{d}, 2 \mathrm{~m} / \mathrm{s} \mathrm{K}$ for $\mathbf{e}$ and $\mathbf{f}$ and $1 \times 10^{-3} \mathrm{~m} / \mathrm{s}$ for $\mathbf{g}$ and $\mathbf{h}$ (a) trend DJF uhvh $250 \mathrm{mb}$ GFDL

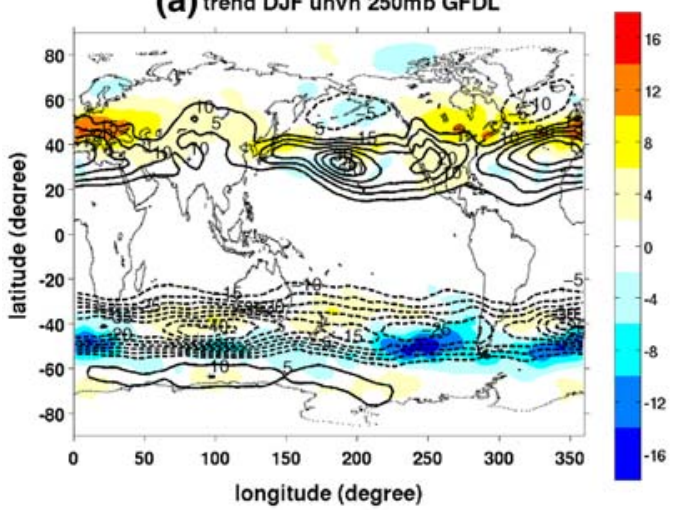

(c) trend DJF vhvh $250 \mathrm{mb}$ GFDL

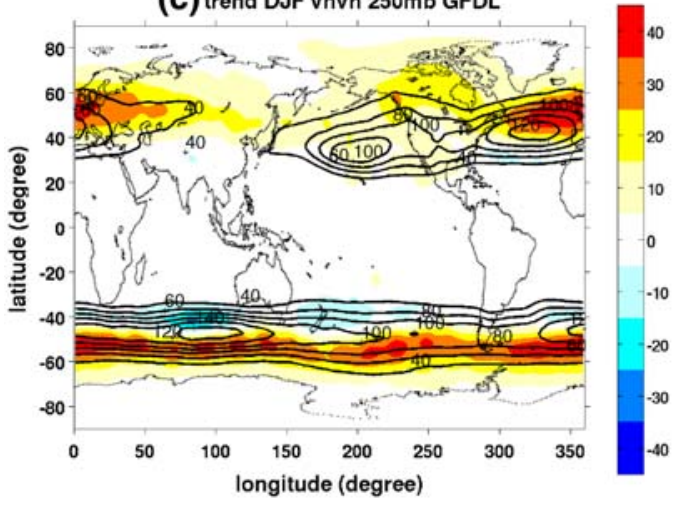

(e) trend DJF vhTh $700 \mathrm{mb}$ GFDL

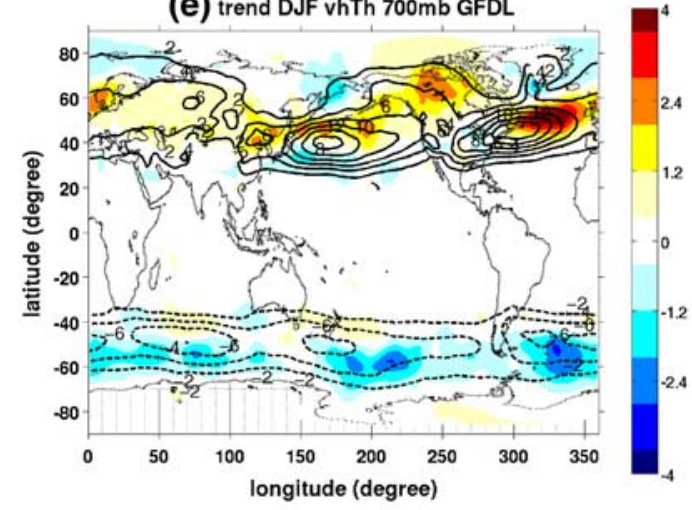

(g) trend DJF $10^{-3}$ vhqh $700 \mathrm{mb}$ GFDL

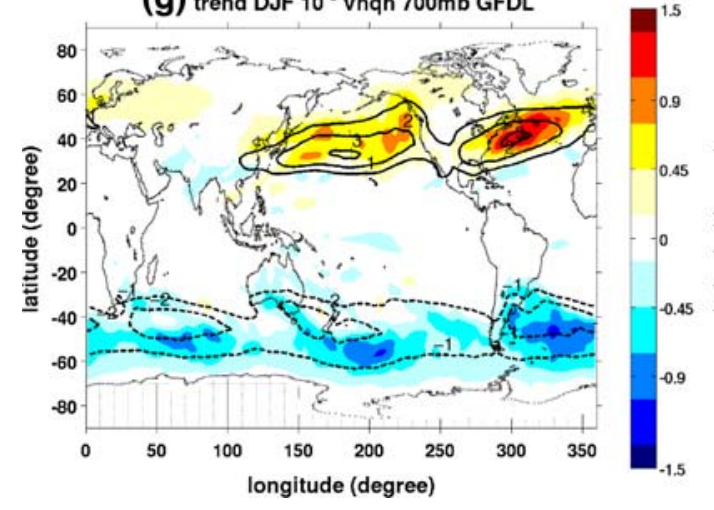

(b) trend JJA uhvh 250mb GFDL

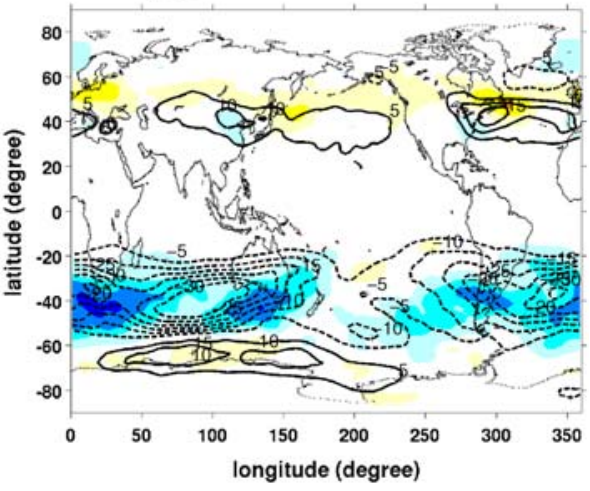

(d) trend JJA vhvh $250 \mathrm{mb}$ GFDL

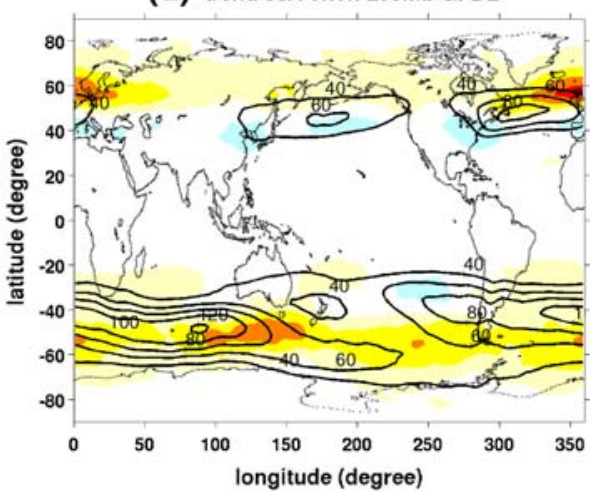

(f) trend JJA vhTh $700 \mathrm{mb}$ GFDL

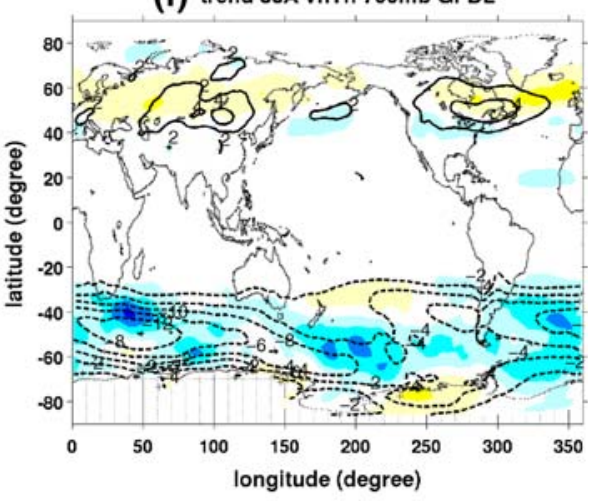

(h) trend JJA $10^{-3}$ vhqh $700 \mathrm{mb}$ GFDL

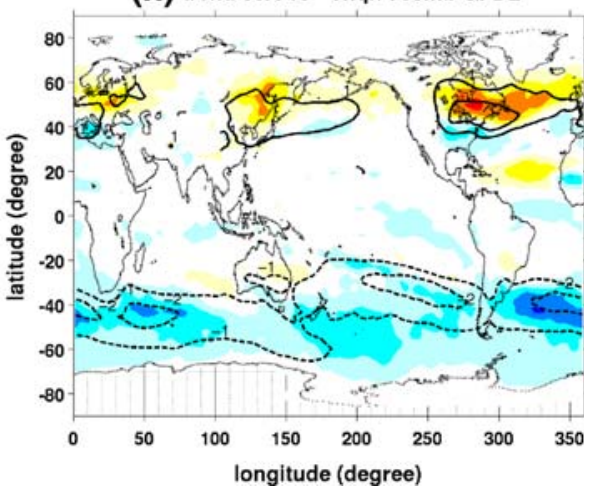


Fig. 3 Same as Fig. 2 but for the twenty-first century trend in zonal mean eddy statistics as a function of latitude and pressure $(\mathrm{mb})$, i.e. $\mathbf{a}$ and $\mathbf{b}\left[\overline{u^{\prime} v^{\prime}}\right]$, $\mathbf{c}$ and $\mathbf{d}$ $\left[\overline{v^{\prime} v^{\prime}}\right]$, e and $\mathbf{f}\left[\overline{v^{\prime} T^{\prime}}\right], \mathbf{g}$ and $\mathbf{h}$ $\left[\overline{v^{\prime} q^{\prime}}\right]$, in DJF and JJA, respectively, plotted in colors, with the 1961-2000 climatology in contours (a) trend DJF uhvh GFDL

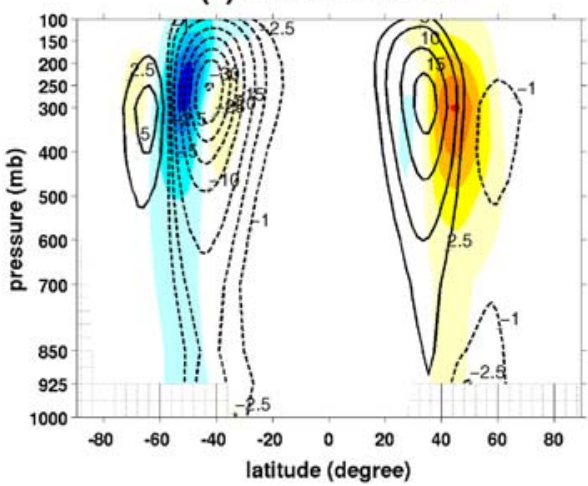

(c) trend DJF vhvh GFDL

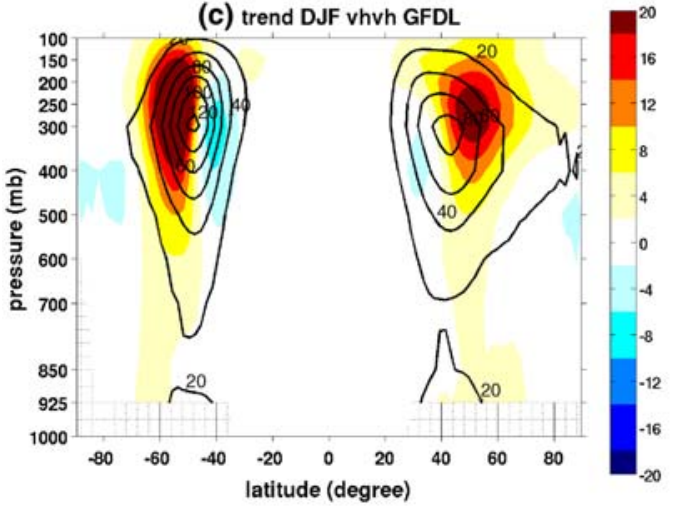

(e) trend DJF vhTh GFDL

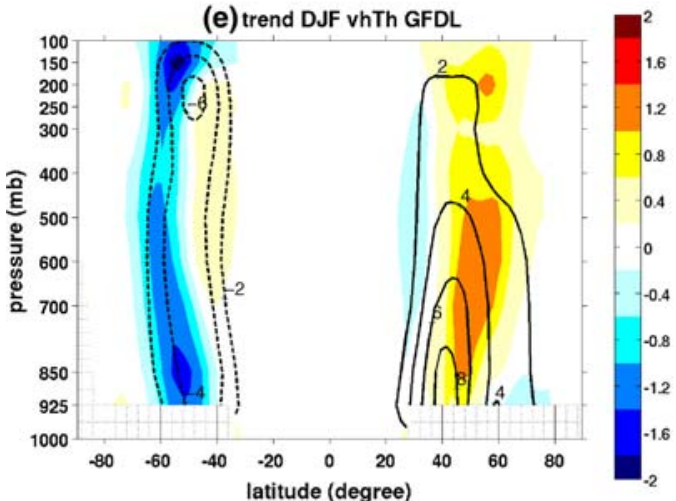

(g) trend DJF $10^{-3}$ vhqh GFDL

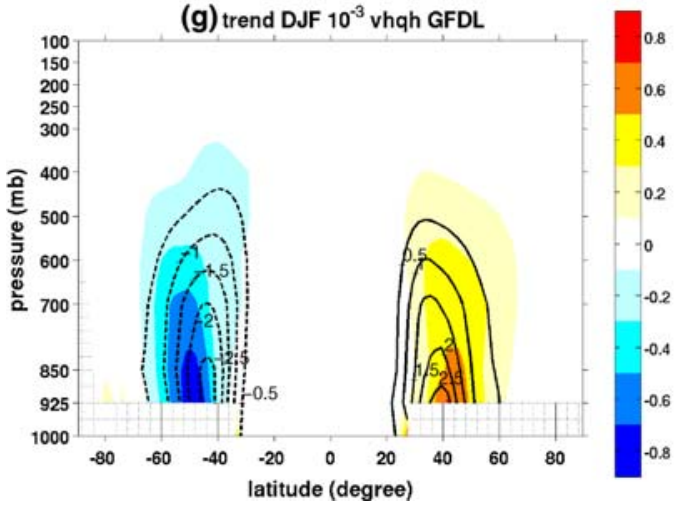

(b) trend JJA uhvh GFDL

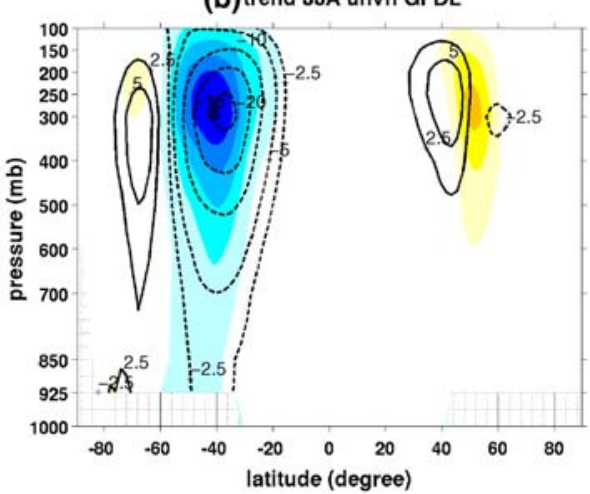

(d) trend JJA vhvh GFDL

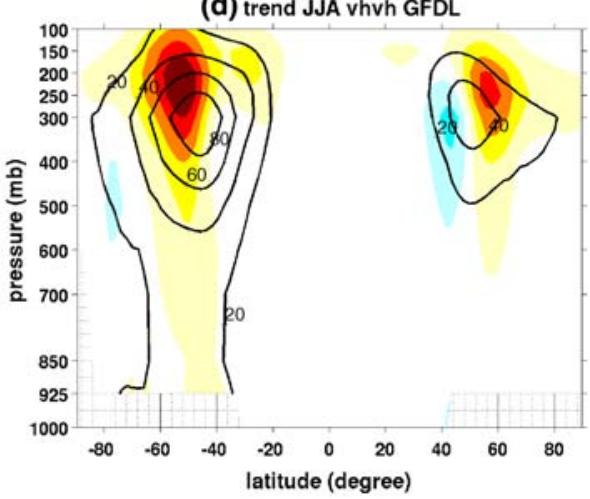

(f) trend JJA vhTh GFDL

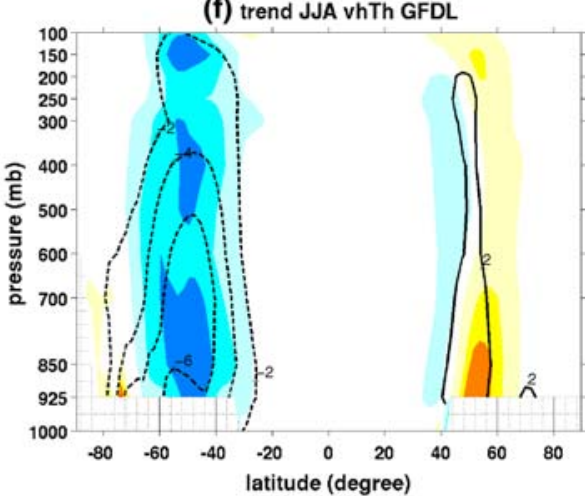

(h) trend JJA $10^{-3}$ vhqh GFDL

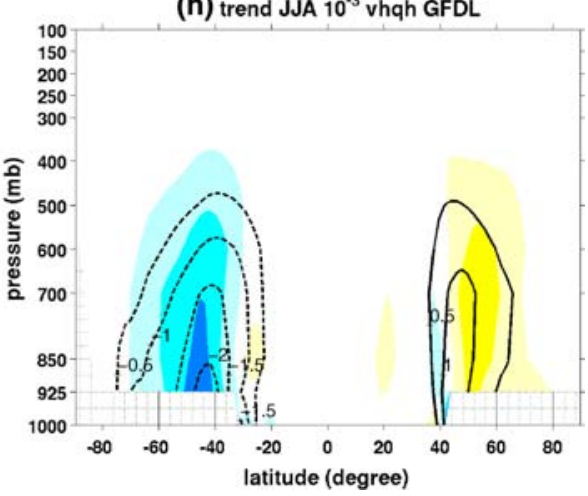

Here we first apply the maximum Eady growth rate to determine the changes in baroclinicity of the mean states in the late twenty-first century from that in the latter half of the twentieth century as simulated in the GFDL CM2.1 model. A simple approximate result for the maximum growth rate of baroclinic instability is given by 
$\sigma_{D}=0.31 g \frac{1}{N} \frac{1}{T}\left|\frac{\partial \bar{T}}{\partial y}\right|$

(Lindzen and Farrell (1980)), where $N$ is the Brunt-Vaisala frequency, a measure of static stability. Figure $4 \mathrm{a}$ and $\mathrm{b}$ show the twenty-first century trend in zonal mean tropospheric temperature $[\bar{T}]$ (colors) as well as the twentieth century climatology (contours). It shows a strong upper tropospheric warming in both seasons and an enhanced Arctic warming in northern winter. The tropical upper tropospheric warming is caused by enhanced tropical convection which transports heat trapped by the additional greenhouse gases upward with the tropical atmosphere retaining a moist adiabatic lapse rate under a warmer condition. The large warming located in the Arctic in winter, where the ice-albedo feedback is weak, is largely a result of large atmospheric static stability concentrating the warming at low levels (Hansen et al. (1984)). The associated climatology and trend in zonal mean meridional temperature gradients $\left|\frac{\partial[\bar{T}]}{\partial y}\right|$ is given in Fig. $4 \mathrm{e}$ and f. Strong gradients of temperature can be seen in the midlatitudes, particularly in the vicinity of the subtropical jet (shown in Figs. $4 \mathrm{c}, \mathrm{d}$ ). The trend in both seasons in both hemispheres demonstrates a poleward shift and intensification in midlatitude meridional temperature gradients. The one exception is in the lower troposphere in northern winter when the warming at the Arctic winter surface leads to a reduced zonal mean meridional temperature gradient there. ${ }^{3}$ Figure $4 \mathrm{~g}$ and $\mathrm{h}$ represent the climatology and trend of the static stability in the atmosphere. The whole lower and middle troposphere becomes more statically stable except for the middle and high latitudes in northern winter. The rising subtropical tropospheric static stability has been related to the poleward expansion of the Hadley Cell by Lu et al. (2007). The reduced static stability in the middle and high latitudes in northern winter is again due to the strong warming near the surface. The jet stream in a warmer climate tends to shift poleward and upward and intensify on the poleward and upward flank of the climatological jet in both seasons in both hemispheres (Fig. 4c, d). This change in the jet stream is consistent with that in the storm tracks. These changes are representative of the changes in the time-mean states of many GCMs with increased greenhouse gases (e.g., Meehl et al. (2007)).

\subsection{Zonal mean structures of baroclinic instability}

As the dry Eady growth rate is determined by both the meridional temperature gradient and static stability, future changes in both terms will impact the change in the

\footnotetext{
3 The zonal mean meridional temperature gradient reduces despite an increase in temperature gradient in the North Atlantic region.
}

baroclinic instability of the time-mean flow. The zonal mean of the dry Eady growth rate is shown in Fig. 5a and b for both DJF and JJA. The climatology maximizes in the midlatitudes and is stronger in the winter hemisphere due to stronger meridional temperature gradients. The change in the dry Eady growth rate follows that in the meridional temperature gradient, i.e. a poleward shift and an intensification on the poleward flank in the middle and upper troposphere of the midlatitudes except for the lower troposphere in northern winter. The contribution from the static stability according to the dry Eady growth rate is small, but the rising tropospheric static stability south of $40^{\circ} \mathrm{N}$ helps to stabilize the subtropical jet streams on the equatorward flank whereas the reduced static stability north of $40^{\circ} \mathrm{N}$ acts to enhance the instability of the jet streams on the poleward flank, which would assist a poleward shift of the storm tracks. Therefore, as can be seen in Fig. 5a and b, the poleward shift and enhancement of the dry Eady growth rate in the midlatitudes of both hemispheres in both seasons (except for the lower troposphere in northern winter) fully supports the storm track changes. The results in Fig. 5a and $\mathrm{b}$ confirm the relevance of the changing characteristics of baroclinic instability in driving the storm track changes. The results further indicate that eddies are influenced by the baroclinicity in the upper troposphere rather than the surface instability, as the enhancement of the instability growth rate in the upper troposphere from 225 to $550 \mathrm{mb}$ well corresponds to the storm track response in this region in terms of $\left[\overline{u^{\prime} v^{\prime}}\right]$ and $\left[\overline{v^{\prime} v^{\prime}}\right]$. However, it is not clear what role the decrease in instability growth rate in the lower troposphere plays in explaining the storm track response in northern winter.

\subsection{Eddy transfer and mean state gradients}

In order to explain that the transient eddy sensible heat transport in the middle latitudes of both hemispheres in both seasons increases as climate warms (Fig. 3e, f) despite the decreased temperature gradients in the lower troposphere in northern winter, we apply mixing length theory in this section to attribute the increasing transient eddy energy transfer to eddy properties and mean state gradients in boreal winter.

Based on the theoretical work of Charney (1947), Eady (1949) and Green (1970) proposed a theory for the largescale eddy transfer, based on eddy mixing, by relating eddy transfer properties to eddy motion and mean gradients as follows:

$\overline{v^{\prime} m^{\prime}}=k\left|v^{\prime}\right|\left|m^{\prime}\right|=k\left|v^{\prime}\right|\left(-L_{\mathrm{mix}} \frac{\partial \bar{m}}{\partial y}\right)=-D \frac{\partial \bar{m}}{\partial y}$

where $v^{\prime} m^{\prime}$ is the meridional transport of any conserved property $m, D$ is defined as the eddy diffusivity, i.e. $D=k$ 
Fig. 4 Same as Fig. 2 but for the twenty-first century trend in zonal mean climatological states, i.e. $\mathbf{a}$ and $\mathbf{b}[\bar{T}], \mathbf{c}$ and $\mathbf{d}$ $[\bar{u}]$, e and $\mathbf{f}\left|\frac{\partial[\bar{T}]}{\partial y}\right|, \mathbf{g}$ and $\mathbf{h}[\bar{N}]$, in DJF and JJA, respectively, plotted in colors, with the twentieth century climatology in contours. Contour intervals are $225 \mathrm{~K}$ for $\mathbf{a}$ and $\mathbf{b}, 5 \mathrm{~m} / \mathrm{s}$ for $\mathbf{c}$ and $\mathbf{d}, 1 \mathrm{~K} / 1,000 \mathrm{~km}$ for $\mathbf{e}$ and $\mathbf{f}$ and $2.5 / 1,000 \mathrm{~s}^{-1}$ for $\mathbf{g}$ and $\mathbf{h}$ (a) trend DJF T GFDL

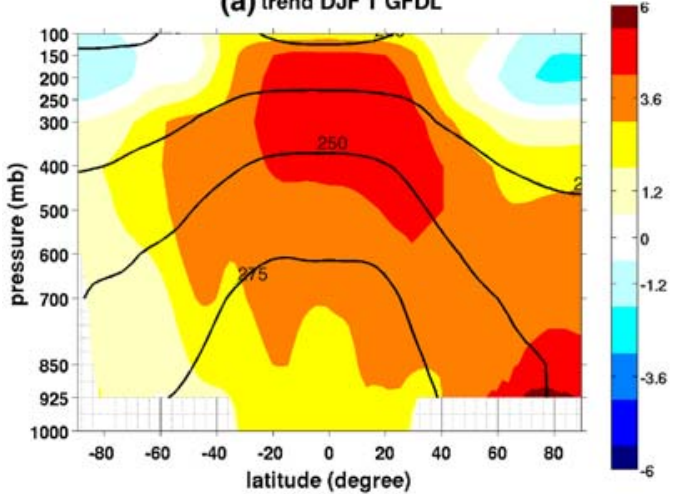

(c) trend DJF u GFDL

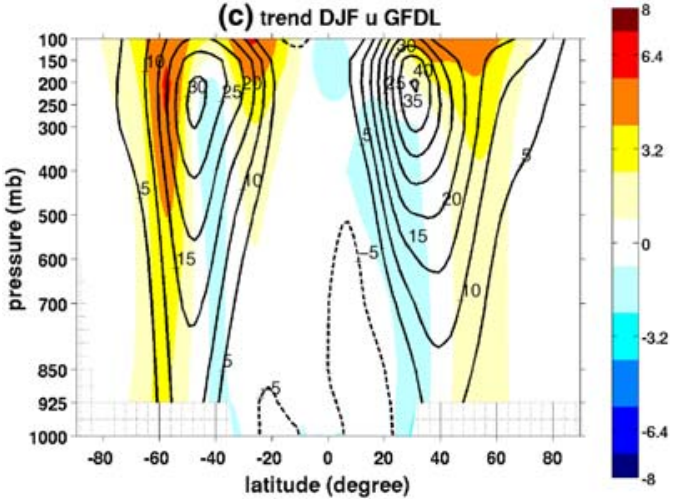

(e) trend DJF /dT/dy| [K/1000km] GFDL

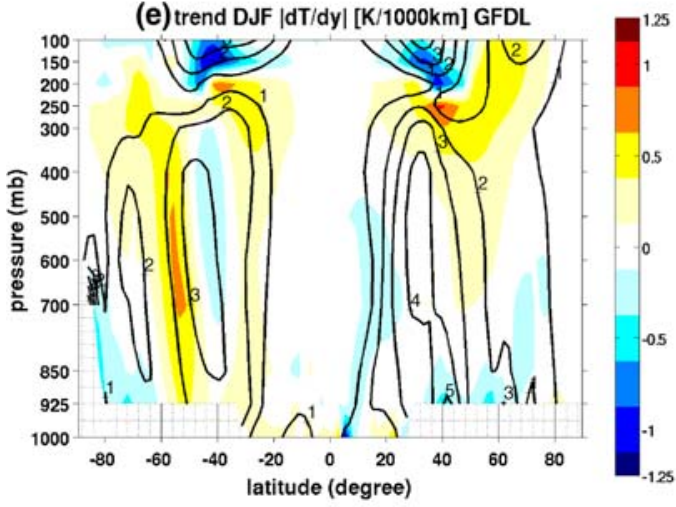

(g) trend DJF N [1/1000s] GFDL

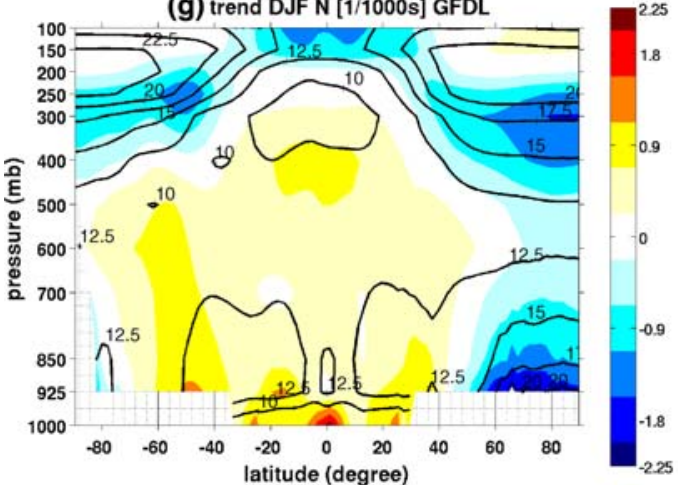

(b) trend JJA T GFDL

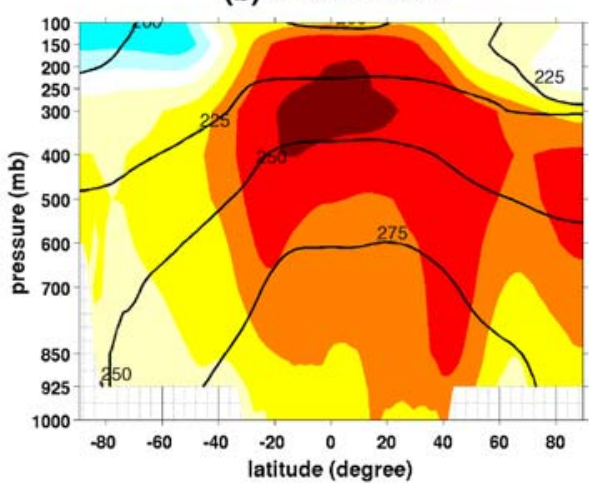

(d) trend JJA u GFDL

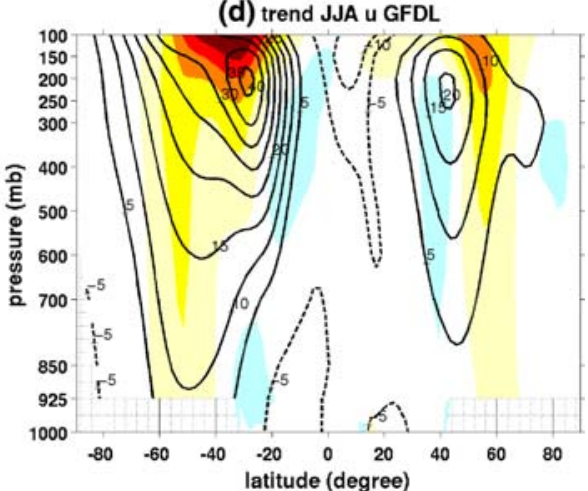

(f) trend JJA $|\mathrm{dT} / \mathrm{dy}|[\mathrm{K} / 1000 \mathrm{~km}]$ GFDL

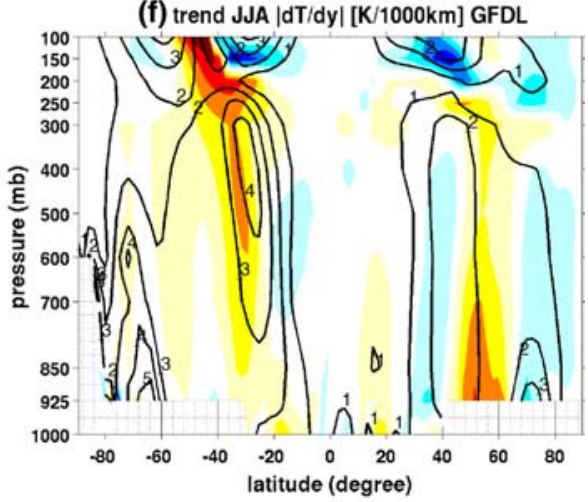

(h) trend JJA N [1/1000s] GFDL

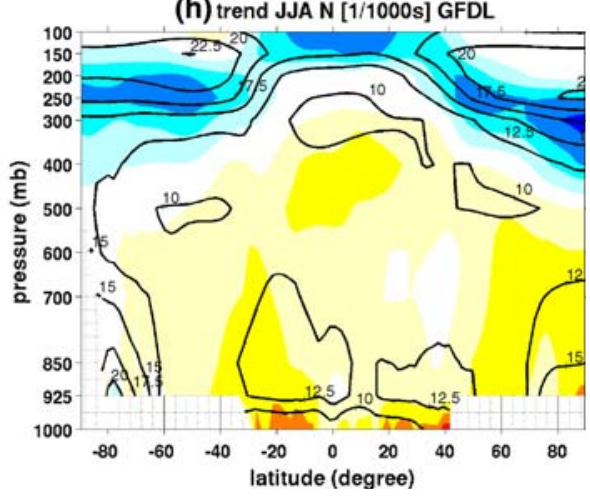

$L_{\text {mix }}\left|v^{\prime}\right|$ with $k$ the correlation coefficient between $v^{\prime}$ and $m^{\prime}$, $L_{\text {mix }}$ the mixing length scale, and $\left|v^{\prime}\right|$ and $\left|m^{\prime}\right|$ rms amplitudes of eddy velocity and $m$, and $\frac{\partial \bar{m}}{\partial y}$ is the time mean state gradient. The complete form in Green (1970) for the transfer in meridional-vertical section has additional contribution from vertical mixing which is neglected here. We apply Eq. 2 to the conserved quantity moist static energy, band-pass filtered transients and zonal mean fields (with 
(a) trend DJF $\sigma_{0}$ GFDL

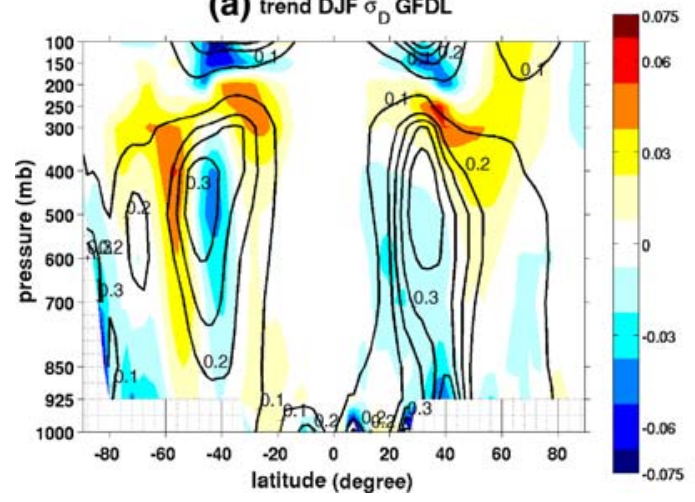

(b) trend JJA $\sigma_{D}$ GFDL

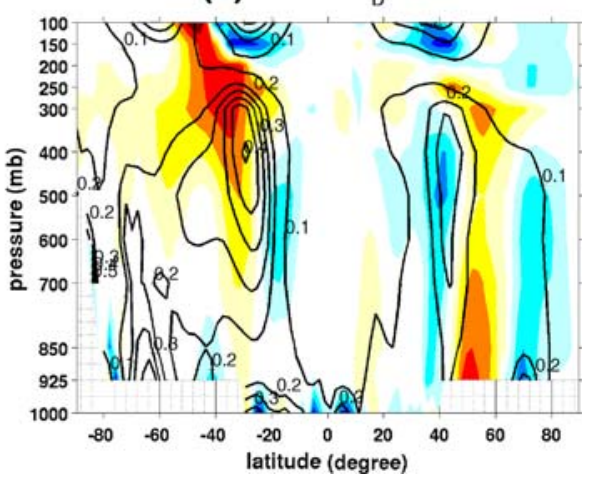

Fig. 5 Same as Fig. 2 but for the twenty-first century trend in zonal mean Eady growth rate $\sigma_{D}$ in (a) DJF and (b) JJA, in colors, with the twentieth century climatology in contours. Contour intervals are 0.5 day $^{-1}$. Units are day ${ }^{-1}$

square brackets denoting zonal averages neglected here) and compute $k$ and $L_{\text {mix }}$ by definition, i.e. $k=\frac{\frac{v^{\prime} m^{\prime}}{v^{\prime} \mid}\left|m^{\prime}\right|}{\text { and }}$ $L_{\text {mix }}=\frac{\left|m^{\prime}\right|}{-\frac{\partial m}{\partial y}}$ for both the twentieth and twenty-first century simulations. Here moist static energy (MSE) is defined as $m=C_{p} T+\Phi+L_{e} q$ with $C_{p}$ the specific heat capacity for the atmosphere, $\Phi$ the geopotential height and $L_{e}$ the latent heat of evaporation. Because of the quasi-geostrophic nature of eddies, the zonally averaged eddy potential energy transfer can be neglected and the transient eddy MSE transport can be written as $\overline{v^{\prime} m^{\prime}} \approx C_{p} \overline{v^{\prime} T^{\prime}}+L_{e} \overline{v^{\prime} q^{\prime}}$. It is noted that the original intention of Eq. 2 is for parameterizing eddy transfer using large-scale quantities. Our study here, however, is using Eq. 2 as a diagnostic tool for understanding the change in transient eddy energy transfer $\left(\overline{v^{\prime} m^{\prime}}\right)$ in terms of correlation coefficient $(k)$, transient eddy velocity $\left(v^{\prime}\right)$, mixing length scale $\left(L_{\text {mix }}\right)$ and mean state gradients $\left(\frac{\partial \bar{m}}{\partial y}\right)$.

Therefore, the change in eddy MSE transport can be written as

$$
\begin{aligned}
\underbrace{\Delta\left(\overline{v^{\prime} m^{\prime}}\right)}_{(a)}= & \Delta\left\{k L_{\text {mix }}\left|v^{\prime}\right|\left(-\frac{\partial \bar{m}}{\partial y}\right)\right\} \\
\approx & \underbrace{\Delta(k) L_{\text {mix }}\left|v^{\prime}\right|\left(-\frac{\partial \bar{m}}{\partial y}\right)}_{(c)}+\underbrace{k \Delta\left(L_{\text {mix }}\right)\left|v^{\prime}\right|\left(-\frac{\partial \bar{m}}{\partial y}\right)}_{(d)} \\
& +\underbrace{k L_{\text {mix }} \Delta\left(\left|v^{\prime}\right|\right)\left(-\frac{\partial \bar{m}}{\partial y}\right)}_{(e)}+\underbrace{k L_{\text {mix }}\left|v^{\prime}\right| \Delta\left(-\frac{\partial \bar{m}}{\partial y}\right)}_{(f)}
\end{aligned}
$$

which decomposes the impact of the change in correlation coefficient [term $(c)$ ], mixing length scale [term $(d)$ ], eddy velocity $[\operatorname{term}(e)]$ and mean MSE gradient [term $(f)]$ on the change in total transient eddy MSE transport. Figure $6 \mathrm{a}$ shows the DJF change in transient eddy MSE transport for the late twenty-first century (colors), with the twentieth century climatology shown in contours. It illustrates an enhanced poleward transient eddy MSE transport in both hemispheres. The sum of terms (c-f) in Eq. 3 is shown in Fig. $6 \mathrm{~b}$ in contours, with the twenty-first century trend in $\overline{v^{\prime} m^{\prime}}$ in colors. The agreement between contours and colors in Fig. $6 \mathrm{~b}$ indicates that the nonlinear contributions ignored on the right hand side of Eq. 3 are insignificant.

When separating the total change in $\overline{v^{\prime} m^{\prime}}$ into contributions from $k, L_{\text {mix }},\left|v^{\prime}\right|$ and $\frac{\partial \bar{m}}{\partial y}$ (Fig. $6 \mathrm{c}-\mathrm{f}$ ), it is found that all of the terms contribute significantly. The colors in Fig. 6c$\mathrm{f}$ indicate the total change as shown in Fig. 6a. The most dominant contribution in the midlatitudes of the Northern Hemisphere comes from the increasing correlation between transient eddy velocity and eddy MSE while in the Southern Hemisphere it is the enhancement of mean state gradients. As shown in Fig. 6f, the reduction in mean energy gradient in the lower-troposphere of the middle and high northern latitudes (caused by a decreased meridional temperature gradient dominating over a specific humidity gradient increase) would reduce the poleward energy transport by the storm tracks. In contrast, in the midlatitudes of the Southern Hemisphere and the mid-troposphere in the Northern Hemisphere, the increase in mean energy gradient would lead to an increase in transient eddy energy transport and this dominates the total in these regions. The contribution from the other three terms in general is positive to the total. In particular, in the lower troposphere of the midlatitude Northern Hemisphere, it is mainly the increasing correlation coefficient, and to a lesser extent, the increasing eddy velocity and mixing length scale that overwhelms the decreasing contribution from the mean gradient and leads to the intensified transient eddy energy transport.

The question to be addressed in the following is what causes the increasing correlation coefficient between 
(a) trend DJF $10^{3}$ vhmh (colors) GFDL DJF 20th $10^{3}$ vhmh (contours)

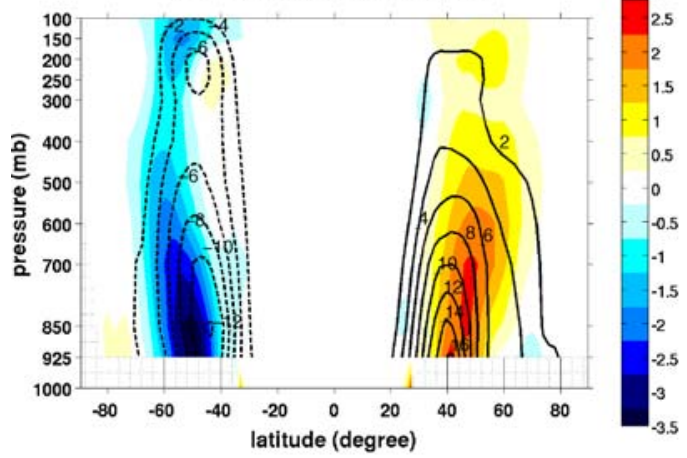

(c) DJF $10^{3} \Delta(\mathrm{k}) \mathrm{L}|\mathrm{vh}|(-\mathrm{dm} / \mathrm{dy})$ (contours) GFDL trend DJF $10^{3} \mathrm{vhmh}$ (colors)

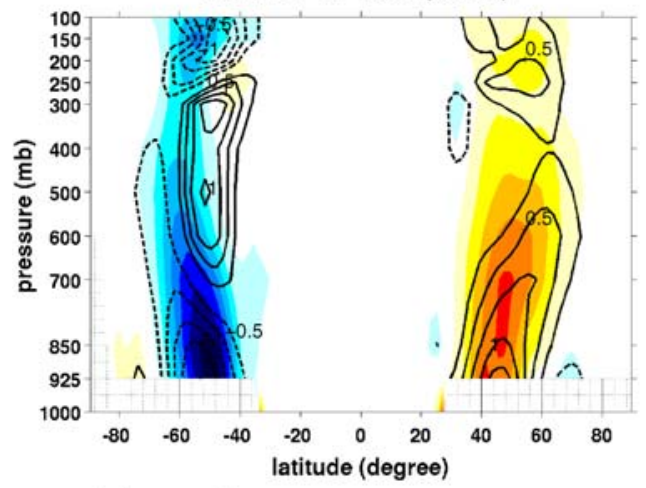

(e) DJF $10^{3} \mathrm{~kL} \Delta(|\mathrm{vh}|)(-\mathrm{dm} / \mathrm{dy})$ (contours) GFDL trend DJF $10^{3} \mathrm{vhmh}$ (colors)

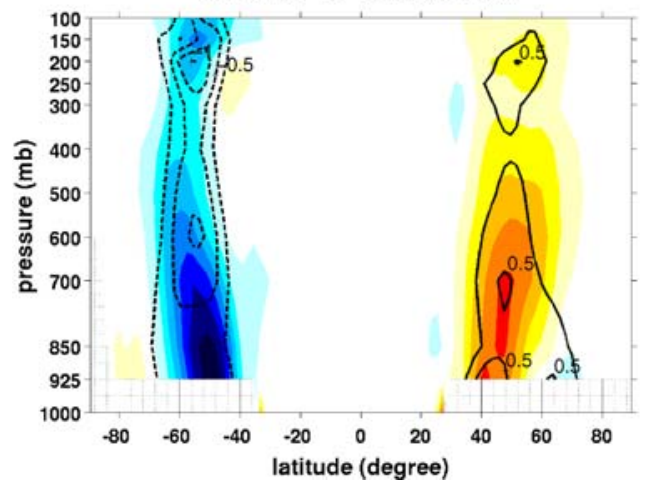

Fig. 6 Shown in contours are a the twentieth century climatology in band-pass filtered transient meridional eddy moist static energy (MSE) transfer $\left[\overline{v^{\prime} m^{\prime}}\right] ; \mathbf{b}$ sum of $\mathbf{c}, \mathbf{d}, \mathbf{e}$ and $\mathbf{f}$ as indicated by the mixing length theory; changes in eddy MSE transfer caused by $\mathbf{c}$ the change in correlation coefficient $k$ between eddy motion $v^{\prime}$ and eddy

transient eddy motion and eddy energy and the increasing mixing length scale as climate warms. It is found that the wave packets in one-point correlation maps (Chang (1993)) become longer in the lower troposphere in the Northern Hemisphere in future projections (not shown), which implies more persistent wave structures and increasing correlation over greater distances. This can also be viewed through a cross-spectral analysis of the lower tropospheric (b) DJF $10^{3}$ (c) + (d) + (e) + (f) (contours) GFDL trend DJF $10^{3} \mathrm{vhmh}$ (colors)

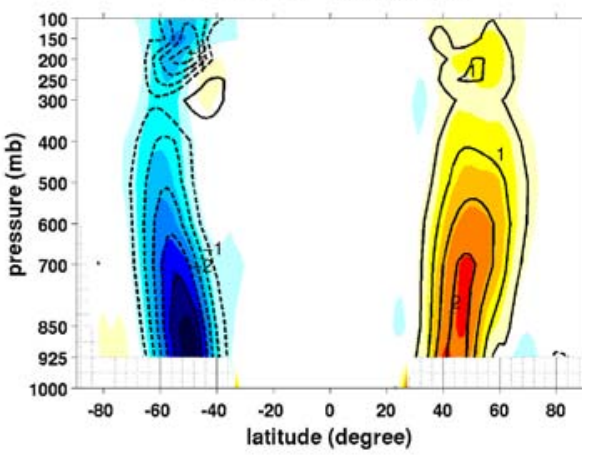

(d) DJF $10^{3} \mathrm{k} \Delta$ (L) |vh| (-dm/dy) (contours) GFDL trend DJF $10^{3} \mathrm{vhmh}$ (colors)

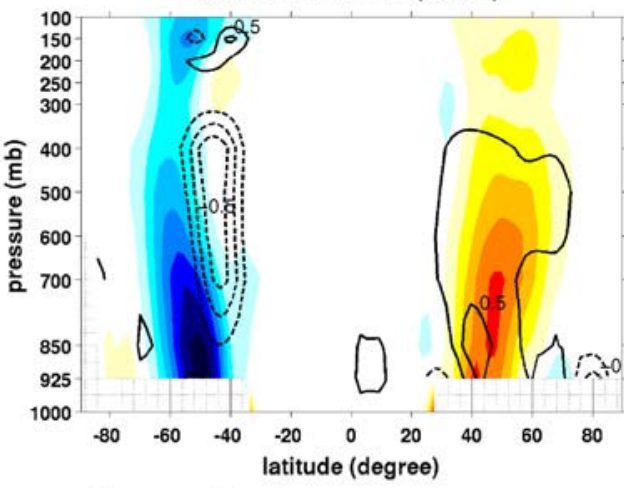

(f) DJF $10^{3} \mathrm{~kL}|\mathrm{vh}| \Delta($-dm/dy) (contours) GFDL trend DJF $10^{3}$ vhmh (colors)

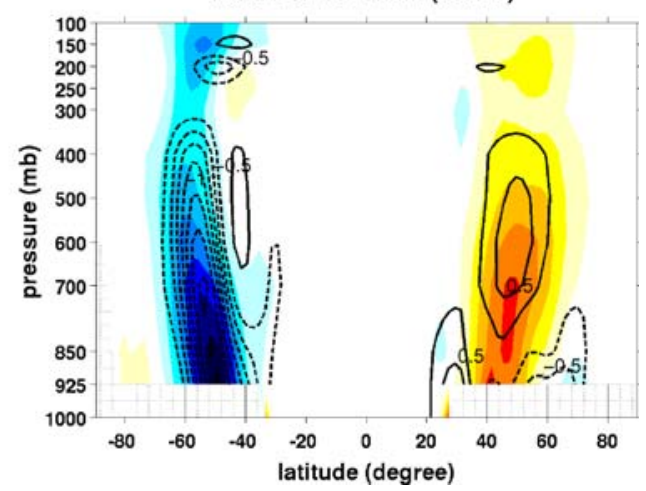

MSE $m^{\prime}$, d the change in mixing length scale $L_{\text {mix }}$, e the change in eddy intensity $\left|v^{\prime}\right|$, and $\mathbf{f}$ the change in mean MSE gradients. Contour intervals are $2 \times 10^{3} \mathrm{~m} / \mathrm{s} \cdot \mathrm{J} / \mathrm{kg}$ for a, $0.5 \times 10^{3} \mathrm{~m} / \mathrm{s} \cdot \mathrm{J} / \mathrm{kg}$ for $\mathbf{b}$ and $0.25 \times 10^{3} \mathrm{~m} / \mathrm{s} \cdot \mathrm{J} / \mathrm{kg}$ for $\mathbf{c}-\mathbf{f}$. Colors in $\mathbf{a}-\mathbf{f}$ are the twenty-first century trend in $\left[\overline{v^{\prime} m^{\prime}}\right]$. Units are $\mathrm{m} / \mathrm{s} \mathrm{J} / \mathrm{kg}$

eddy MSE transfer as in Randel and Held (1991). Figure 7 shows a zonal wavenumber-frequency contour diagram for $\frac{1}{C_{p}} \overline{v^{\prime} m^{\prime}}$ at $700 \mathrm{mb}$, averaged over the midlatitudes between $40^{\circ} \mathrm{N}$ and $60^{\circ} \mathrm{N}$ in DJF, with the twentieth century climatology in black contours and the twenty-first century trend in red. The climatological cross-spectrum shows a strong covariance for eastward propagating waves of zonal 
wavenumber 7 and with a time scale of $4-5$ days. In future projections, there is an increase in spectral power in part of the spectrum related to longer wavelengths and longer time scales. This intensification in smaller zonal wavenumbers is also true for the lower-level transient eddy velocity variance (not shown) and the upper troposphere transient eddy momentum flux (Chen et al. (2008)). Although the reason is not entirely clear, previous studies have shown that the growth rate of baroclinic eddies can depend on the basic state vertical shear and stratification in the stratosphere and the tropopause height (Harnik and Lindzen 1997; Vallis 2006; Wittman et al. 2007; Kunz 2008), all of which are expected to change under global warming. Some results here well correspond to the explanation that in a warmer climate longer waves become more baroclinically unstable and subsequently transport more moist static energy to the poles. The detailed mechanisms will be explored in the future.

In summary, although the midlatitude lower-level temperature gradient reduces in northern winter, the transient eddy poleward energy transfer intensifies as climate warms. As suggested by the mixing length theory, it mainly generates from the contributions of the increasing coherence between transient eddy motion and eddy energy, and to a lesser extent, the increasing eddy velocity and eddy mixing length scale, sum of which overwhelms the reduced mean state gradients.

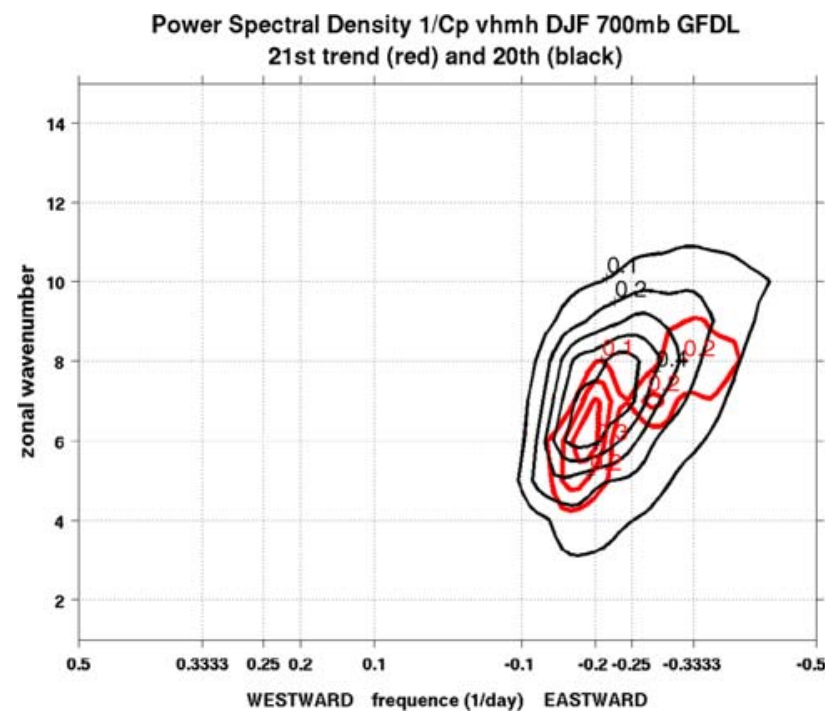

Fig. 7 The global warming trend in transient eddy poleward moist static energy (MSE) transfer (normalized by $C_{p}$ ), i.e. $\frac{1}{C_{p}}\left[\overline{v^{\prime} m^{\prime}}\right]$, as a function of zonal wavenumber and frequency, at $700 \mathrm{mb}$, averaged over the midlatitudes between $40^{\circ} \mathrm{N}$ and $60^{\circ} \mathrm{N}$, in DJF, plotted in red contours, with the twentieth century climatology in black contours. Contour intervals are $0.1 \mathrm{~m} / \mathrm{s} \mathrm{K}$ day. Positive and negative frequency correspond to westward and eastward propagation, respectively

\section{Links between changes in storm tracks and changes in the energy transports}

\subsection{Changes in the energy budget of the atmosphere}

The latitudinal distribution of the radiation budget at the top of the atmosphere (TOA) balances the meridional divergence of atmospheric and oceanic energy transports. In the future climate, the distribution and amplitude of the energy fluxes at the TOA and at the surface, including both radiative and non-radiative fluxes, is expected to change. The midlatitude storm tracks, as part of the global largescale general circulation, are expected to change as well. In this section, we study the mechanisms for the future storm track projections from the perspective of the energy budget of the atmosphere. By combining the total atmospheric energy transport with the radiative fluxes at the TOA and at the surface, and the surface sensible and latent heat fluxes, a diagnosis of the latitude-by-latitude energy budget for the future climate can be performed and compared with that for the current climate.

Hall et al. (1994) examined the total zonal mean poleward energy transport in both control and doubled carbon dioxide experiments by using the UK Meteorological Office GCM with a mixed-layer slab ocean model and found slight differences. The planetary energy budget requirements are satisfied by this difference which is mainly due to increased latent heat transport by transient eddies. Here we examine the changes in atmospheric energy transport in the GFDL CM2.1 model and, building on Hall et al. (1994), link these to changes in the TOA radiative and surface fluxes.

Figure 8(top) gives a summary of the global energy balance and changes due to global warming. The values inside the arrows are the global annual mean for years 1961-2000 from the GFDL CM2.1 model simulations and the values outside the arrows show the corresponding changes from the twentieth century to the twenty-first century (to be discussed later). The positive or negative signs of relative changes are with respect to the climatological direction of energy fluxes. The model's simulations of these radiative and non-radiative fluxes in the current climate compare reasonably well with observations (e.g., Trenberth et al. 2001, 2009). Figure 8(bottom) shows the corresponding latitudinal distribution of the annual and zonal mean energy fluxes, where the net energy flux into the atmosphere $\left(F_{a t m}^{\text {net }}\right)$ is defined as $F_{\text {atm }}^{\text {net }}=R_{T O A}-R_{\text {surface }}+S H+L H$. The top of the atmosphere radiation $\left(R_{T O A}\right)$ shows a net gain of solar radiation in the tropics and subtropics and a net loss of terrestrial radiation in the high latitudes. The net radiative flux at the surface $\left(R_{\text {surface }}\right)$ is almost everywhere positive downward, indicating a net gain of radiation by the surface in the 

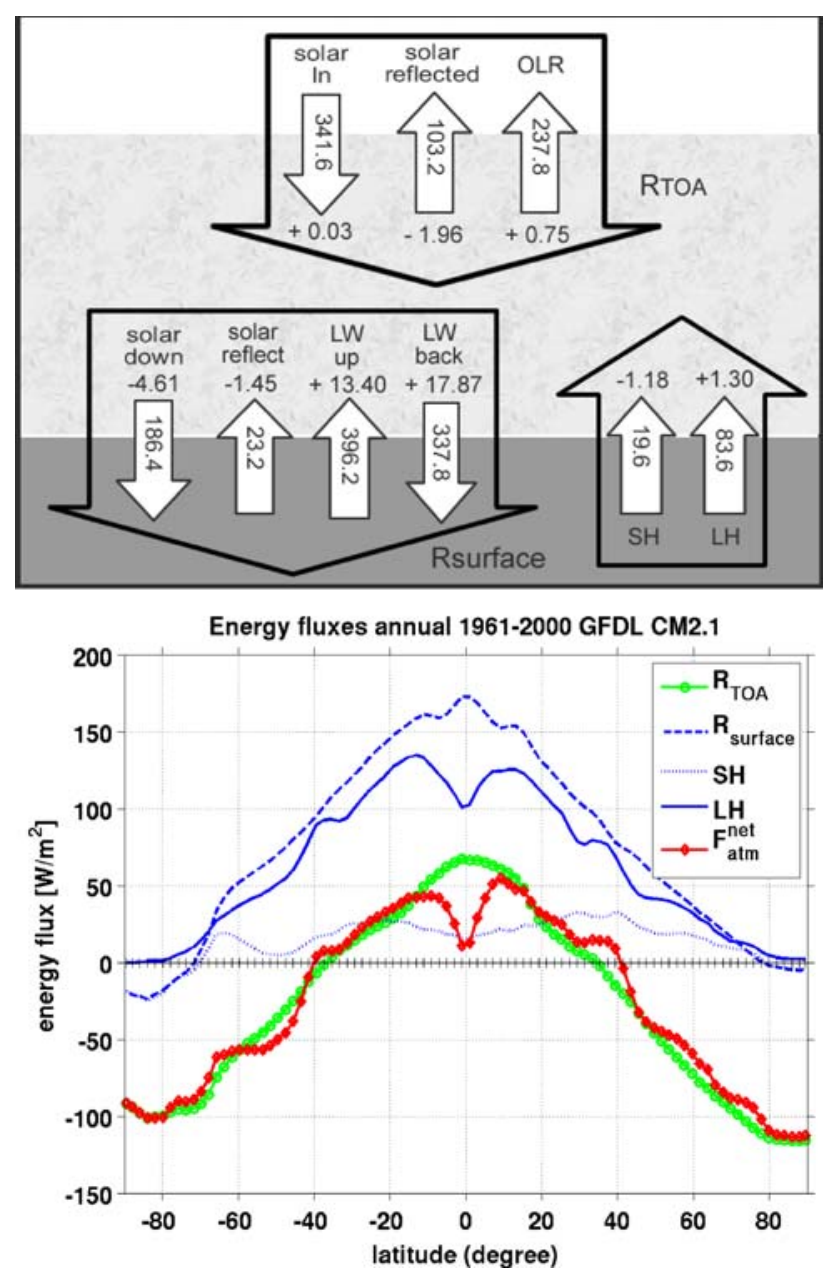

Fig. 8 Top summary of the global energy balance illustrating the notation and direction of energy fluxes. At the top of the atmosphere (TOA), the net downward radiative flux $R_{T O A}$ (positive downward) is made up of the incoming and reflected solar radiation and the outgoing longwave radiation (OLR). The surface flux is made up of the net radiative flux $R_{\text {surface }}$ (positive downward), the surface sensible heat flux SH (positive upward) and the surface latent heat flux $\mathrm{LH}$ (positive upward). The surface radiative flux is comprised of the downward solar radiation, the surface reflected solar radiation, the surface emitted longwave radiation, the longwave radiation emitted back from the atmosphere. The values inside and outside the arrows are the global annual mean for years 1961-2000 and relative changes from years 1961-2000 to 2081-2100, respectively, from the GFDL CM2.1 model simulation. Positive or negative signs in relative changes are with respect to the climatological direction of energy fluxes. Bottom annual and zonal mean energy fluxes for years 19612000 . It comprises $R_{T O A}, R_{\text {surface }}, \mathrm{SH}, \mathrm{LH}$ and the net energy flux into the atmosphere $F_{a t m}^{\text {net }}$. Units are $\mathrm{W} / \mathrm{m}^{2}$

form of net solar and terrestrial radiation. It is balanced by the loss of energy into the atmosphere in terms of upward sensible $(S H)$ and latent heat fluxes $(L H)$. The net energy flux into the atmosphere maximizes in the tropics and has a local minimum around the equator due to the presence of strong ocean heat divergence and suppressed surface latent heat flux (Seager et al. 2003). The seasonal energy fluxes are similar except for hemispheric shifts (not shown).

In response to global warming it is expected that each component of the energy fluxes will change as a consequence of increased greenhouse gases. Figure 9 shows the zonal mean trend from the twentieth to the twenty-first century of all the energy fluxes. Figure 10, as an aid to interpretation, shows the twenty-first century trend in zonal mean precipitation and total cloud fraction. As projected by the GFDL CM2.1 model simulations, the downward radiative flux at the TOA $\left(R_{T O A}\right)$ increases by about $2 \mathrm{~W} / \mathrm{m}^{2}$ in the tropics and subtropics between $40^{\circ} \mathrm{S}$ and $40^{\circ} \mathrm{N}$ in DJF (Fig. 9a). This is caused by a reduction in solar reflection (except equatorial deep convective region) due to reduced cloud cover (shown in Fig. 10a) and a reduction in outgoing longwave radiation (OLR) around the equator due to enhanced deep convection. On the contrary, $R_{T O A}$ decreases at the middle and high latitudes in both hemispheres. In the Northern Hemisphere, the reduction in $R_{T O A}$ comes from the increased OLR which follows the surface terrestrial radiation, whereas in the Southern Hemisphere it is the increased cloudiness and resulting increased solar reflection that reduces the TOA radiation gain. This increase in radiative gain in the tropics and subtropics and radiative loss in the middle and high latitudes is an important factor in determining the change in atmospheric poleward energy transport (to be discussed).

At the surface, the downward radiative flux is expected to increase almost everywhere on Earth because of the increased downward longwave emission from the atmosphere but is offset at the middle and high latitudes of the summer hemispheres where increased cloudiness reflects more solar radiation to space. A notable change in surface non-radiative fluxes is the reduction in both upward sensible and latent fluxes in both seasons over the Southern Ocean. This is consistent with the results of Russell et al. (2006a) who used the same model to show increased ocean heat uptake in response to increased greenhouse gases via increased ocean upwelling (forced by stronger westerlies), which reduces the air-sea temperature and humidity gradients. In addition, it is interesting to note that the partition between surface sensible and latent heat fluxes in response to global warming is seasonally and geographically dependent in the Northern Hemisphere. In northern winter, the evaporation over the ocean in general (except the North Atlantic ocean) increases as a result of increased greenhouse effect whereas the upward sensible heat flux reduces up to $70^{\circ} \mathrm{N}$ due to reduced land-sea temperature contrast and increases north of $70^{\circ} \mathrm{N}$ because of the sea ice melting (Fig. 9b). In northern summer, the increased subtropical drying (e.g., Gregory et al. 1996; Held and Soden 2006; Seager et al. 2007) tends to 
(a) trend DJF energy fluxes GFDL

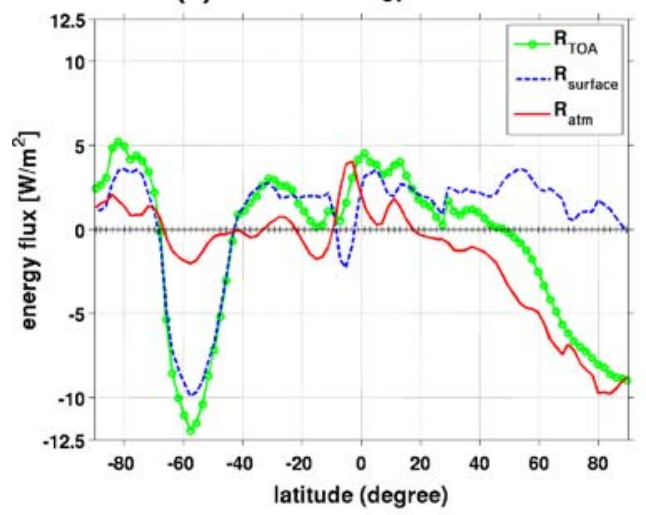

(c) trend JJA GFDL

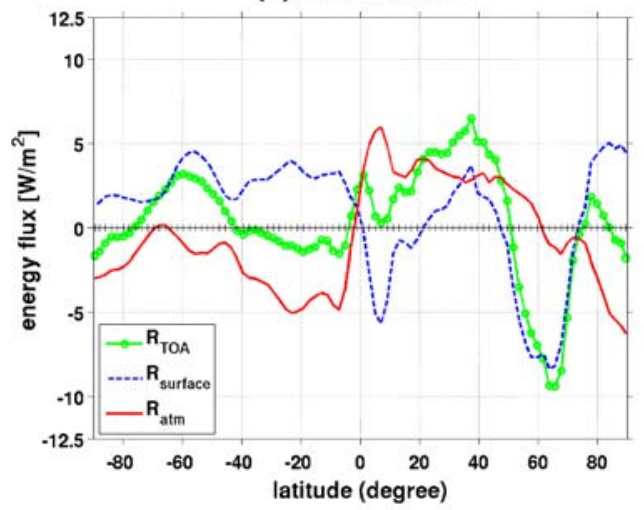

(e) trend annual GFDL

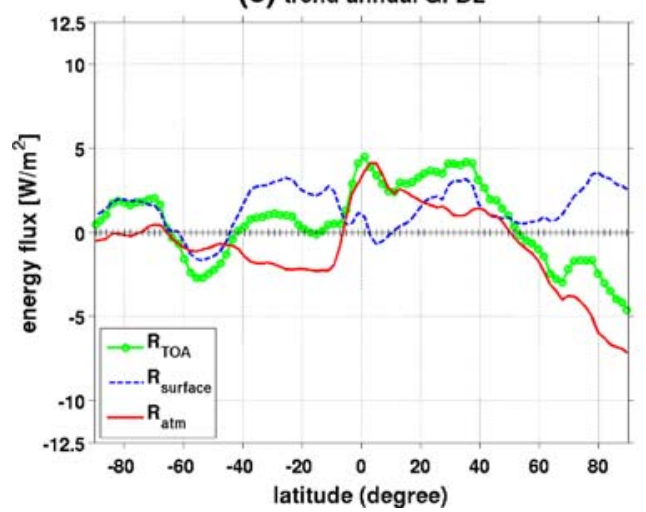

Fig. 9 Global warming trend in zonal mean energy fluxes, i.e. a, c, e $R_{T O A}, R_{\text {surface }}$ and the net radiative flux into the atmosphere $R_{\text {atm }}$, and b, d, f SH, LH and the net energy flux into the atmosphere $F_{a t m}^{\text {net }}$, in

increase the upward sensible heat flux and decrease the evaporation over land, especially around the latitude band of $40^{\circ} \mathrm{N}$. In contrast, there is a reduction in sensible heat flux and an increase in latent heat flux over land between about $60^{\circ} \mathrm{N}$ and $80^{\circ} \mathrm{N}$ because of moistening of continental land masses (Fig. 9d).

As a consequence of the TOA radiation, the surface radiation, and sensible and latent heat fluxes, the net energy flux into the atmosphere is found to increase within the tropics and subtropics between about $40^{\circ} \mathrm{S}$ and $40^{\circ} \mathrm{N}$ and (b) trend DJF energy fluxes GFDL

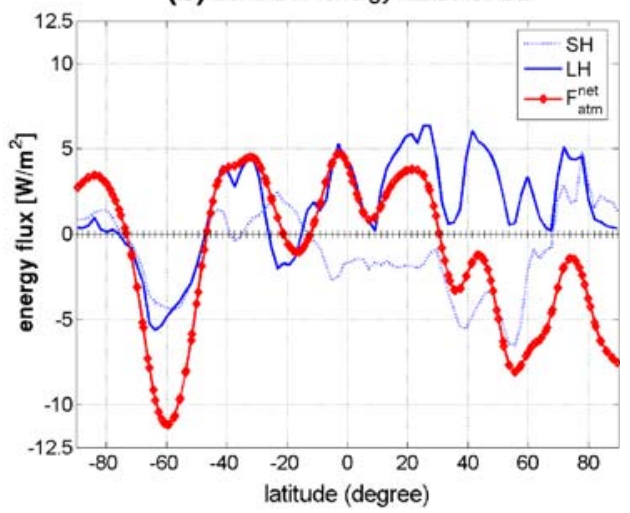

(d) trend JJA energy fluxes GFDL

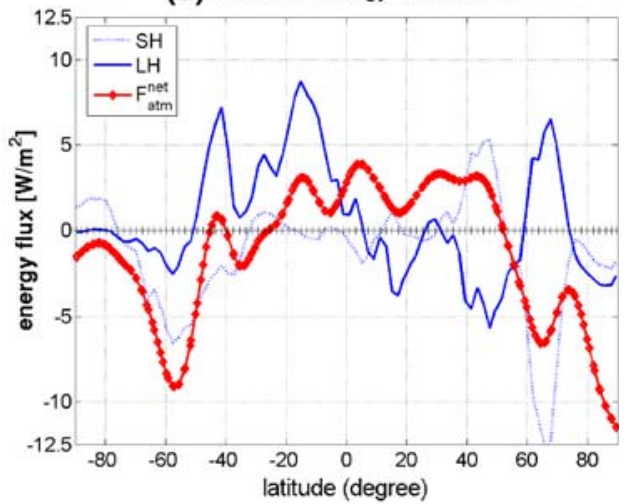

(f) trend annual energy fluxes GFDL

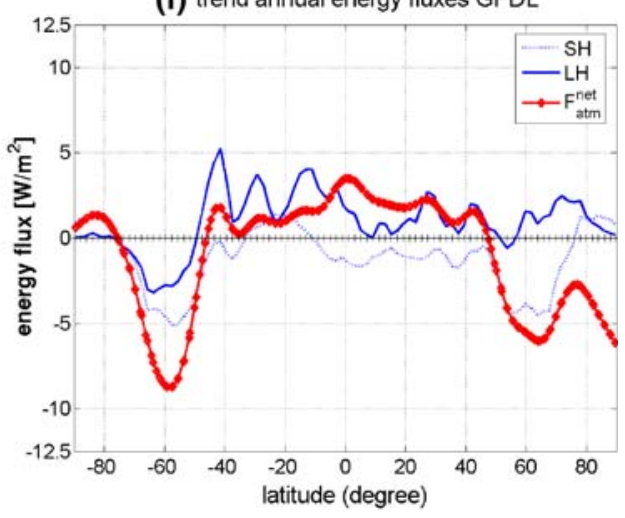

DJF, JJA and annual mean, respectively. Units are $\mathrm{W} / \mathrm{m}^{2}$. A cubic smoothing spline has been applied to the trend of $F_{a t m}^{\text {net }}$ to remove small scale noises

decrease elsewhere in both seasons (Fig. 9b, d, f). ${ }^{4}$ Consequently the gradient between the energy surplus in the tropics and subtropics and the energy deficit at the middle and high latitudes becomes greater in the future climate independent of season. Furthermore, the enhanced energy imbalance in the future climate is primarily radiative

\footnotetext{
${ }^{4}$ In order to pick out the major feature of the change in $F_{a t m}^{n e t}$, a cubic smoothing spline has been applied to it in the meridional direction to remove small scale noises.
} 
(a) trend DJF GFDL

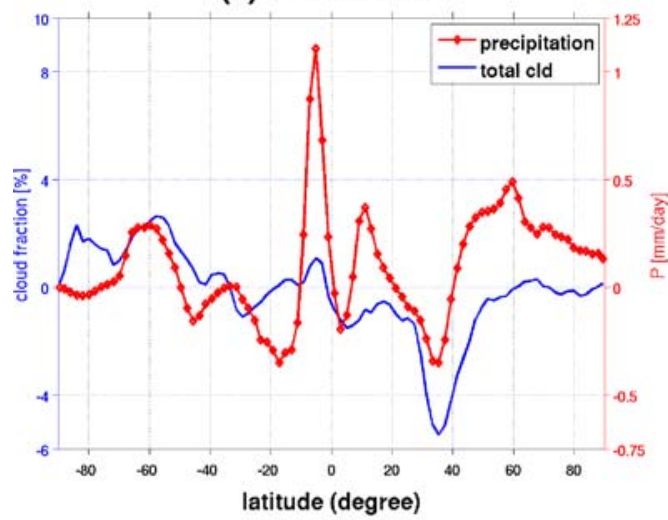

(c) trend annual GFDL

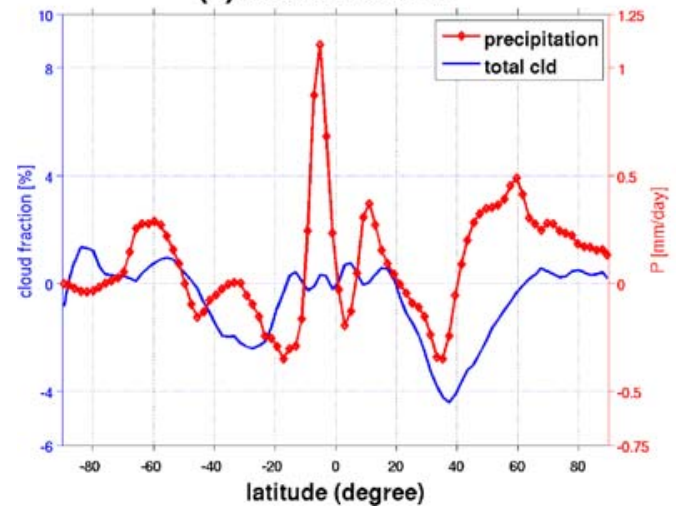

(b) trend JJA GFDL

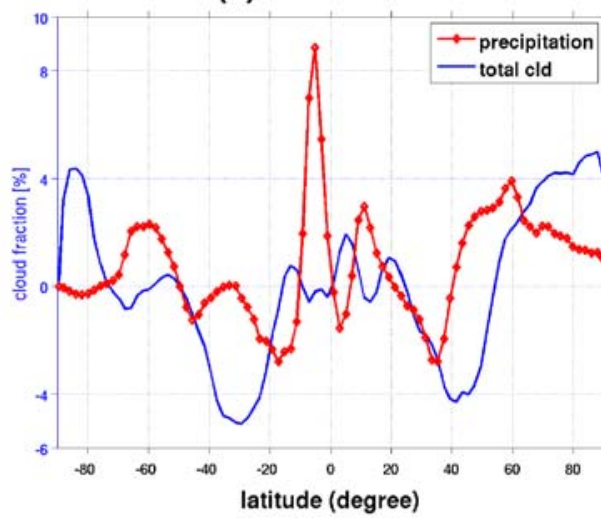

Fig. 10 Global warming trend in zonal mean total cloud fraction (in unit of \%) and precipitation (in unit of mm/day), in a DJF, b JJA and $\mathbf{c}$ the annual mean, from the GFDL CM2.1 model simulations

driven. To achieve an equilibrium state, the total atmospheric energy transport from the equator to the poles must increase. This can be accomplished, all or in part, by intensified transient eddy heat transport.

\subsection{Changes in the atmospheric energy transport}

In this section we quantitatively measure the amount of increased energy transport in the atmosphere required by the energy budget change and examine how it is partitioned among the mean meridional circulation and transient and stationary eddies. We will demonstrate that the increased atmospheric energy transport is concentrated in mid-latitudes and is partially accomplished by the intensified transient eddies, particularly the storm tracks in both seasons in both hemispheres.

The total atmospheric energy transport was first estimated based on the energy budget of the atmosphere as follows:

$S_{A}=F_{a t m}^{n e t}-\nabla \cdot F_{A}$

where $S_{A}$ is the energy storage rate in the atmosphere and $F_{A}$ is the total atmospheric energy transport. Although the atmospheric heat content increases during the latter half of the twentieth century due to anthropogenic warming (e.g., Levitus et al. (2001)), it is at least one order of magnitude smaller than the net energy flux into the atmosphere and is neglected. Averaged over a time period and over longitude domain, $\left[\overline{F_{A}}\right]$ satisfies

$\frac{1}{R \cos \phi} \frac{d}{d \phi}\left(\left[\overline{F_{A}}\right] \cos \phi\right)=\left[\overline{F_{a t m}^{n e t}}\right]$

where $R$ is the Earth's radius and $\phi$ is latitude. Integrating from any specific latitude $\phi_{o}$, the energy transport in the atmosphere across any latitudinal wall $\phi$, denoted by $\left[\overline{T_{A}^{E B}}\right]$, can therefore be written as

$$
\begin{aligned}
{\left[\overline{T_{A}^{E B}}\right] } & =2 \pi R \cos \phi\left[\overline{F_{A}}\right] \\
& =2 \pi R^{2} \int_{\phi_{o}}^{\phi}\left[\overline{F_{\text {atm }}^{\text {net }}}\right] \cos \phi d \phi+\left.\left[\overline{T_{A}^{E B}}\right]\right|_{\phi_{o}}
\end{aligned}
$$

where $\left.\left[\overline{T_{A}^{E B}}\right]\right|_{\phi_{o}}$ is an integral constant and is the total atmospheric energy transport at latitude $\phi_{o}$. The integral is commonly taken from the North Pole where $\left.\left[\overline{T_{A}^{E B}}\right]\right|_{\phi_{o}=\frac{\pi}{2}}=0$ (e.g., Hall et al. (1994)) and corrections are made to eliminate the occurrence of spurious nonzero transports of energy at both poles (Carissimo et al. (1985)). In this case, the 
Fig. 11 Estimates of the total atmospheric energy transport, i.e. $\left[\overline{T_{A}^{E B}}\right]$ derived from the energy budget of the atmosphere and $\left[\overline{T_{A}}\right]$ derived directly from daily data (more in the text), and the energy transport in the atmosphere from the mean meridional circulations (MMC), the storm tracks (band-pass filtered transient eddies with period of 2-8 days), the low-frequency eddies (difference between total transient eddies and the storm tracks) and the stationary waves, for a December-February (DJF), b June-August (JJA) and $\mathbf{c}$ the annual mean, respectively, during years 1961-2000 from the GFDL CM2.1 model simulations. Units are PW

integral constant is determined with respect to the atmospheric energy transport derived from daily data in the model, for example, at the Equator, to ensure accurate estimates. Figure 11 shows $\left[\overline{T_{A}^{E B}}\right]$ for DJF, JJA and the annual mean during the years 1961-2000 and is broadly consistent with the estimates of the meridional atmosphere heat transport in Trenberth and Caron (2001).

For the second method, the total atmospheric energy transport is computed directly from the daily data of velocity, temperature and humidity by integrating the energy transport throughout the whole atmosphere column on hybrid coordinates (Delworth et al. (2006); Lin (2004)). It, denoted by $\left[\overline{T_{A}}\right]$ can be written as

$\left[\overline{T_{A}}\right]=2 \pi R \cos \phi \frac{1}{g} \int_{0}^{p_{s}}\left[\overline{F_{E \phi}}\right] d p$

where $\left[\overline{F_{E \phi}}\right]=[\overline{v E}]=C_{p}[\overline{v T}]+[\overline{v \Phi}]+L_{e}[\overline{v q}]+[\overline{v K}]$ which comprises the meridional transport of sensible heat, geopotential energy, latent heat and kinetic energy $K$. It is also shown in Fig. 11 and agrees well with the estimates from the energy balance requirement. The total atmospheric energy transport is furthermore decomposed into the contributions from different dynamical processes such as the mean meridional circulation (MMC), the transient eddies and the stationary waves, i.e. $[\overline{v E}]=[\bar{v}][\bar{E}]+\left[\overline{v^{\prime} E^{\prime}}\right]+\left[\bar{v}^{*} \bar{E}^{*}\right]$, where $*$ denotes the deviation from zonal average. The storm tracks are the high-frequency part of the transient eddies and the low-frequency component in this study is defined as the difference between the total transient eddies and the storm tracks. The twentieth century climatology for each term is shown in Fig. 11, in which the energy transport by transient eddies in large part dominates the atmospheric energy transport in mid-latitudes while the mean meridional circulation transports a large amount of energy to the poles in the tropics. It is also noted that the midlatitude heat transport within the high-frequency transient eddies is as large as that in stationary waves and is smaller than that in low-frequency eddies. Figure 12 shows the corresponding trend for each term. The total atmospheric energy transport increases almost everywhere across the globe in the late twenty-first century, especially in the regions of the mid-latitudes where eddies dominate the energy transport in the atmosphere. With respect to the contribution from each dynamical (a) Atmospheric Energy Transport DJF 1961-2000 GFDL

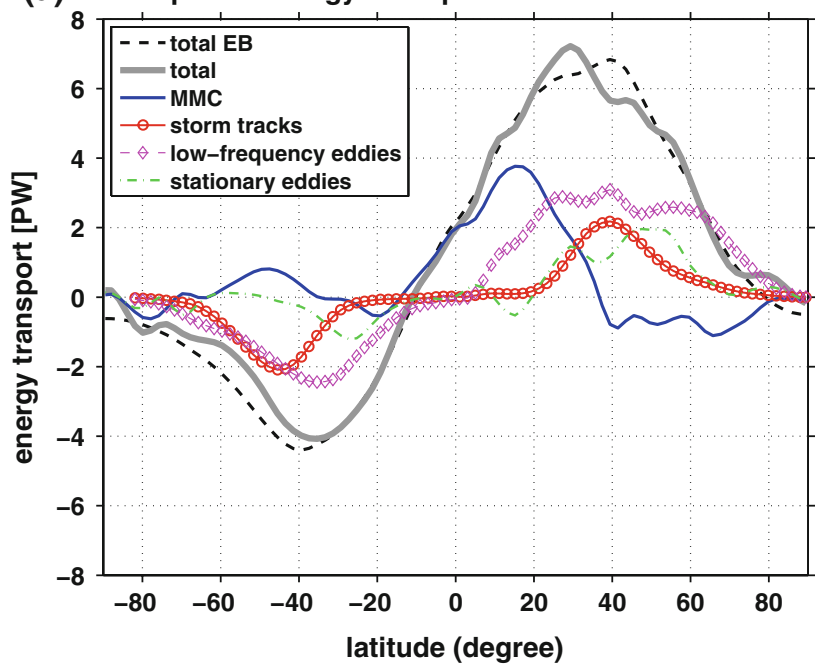

(b) Atmospheric Energy Transport JJA 1961-2000 GFDL

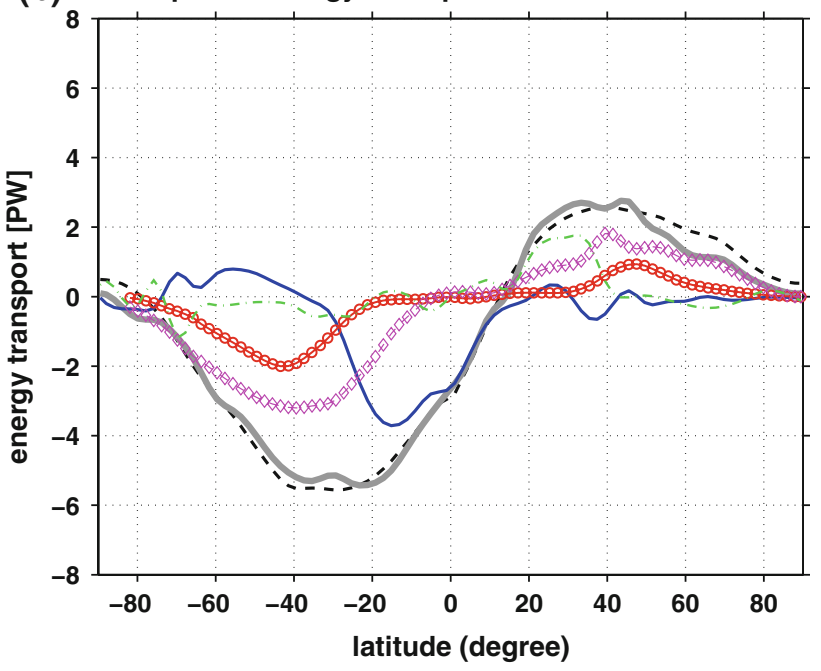

(c) Atmospheric Energy Transport annual 1961-2000 GFDL

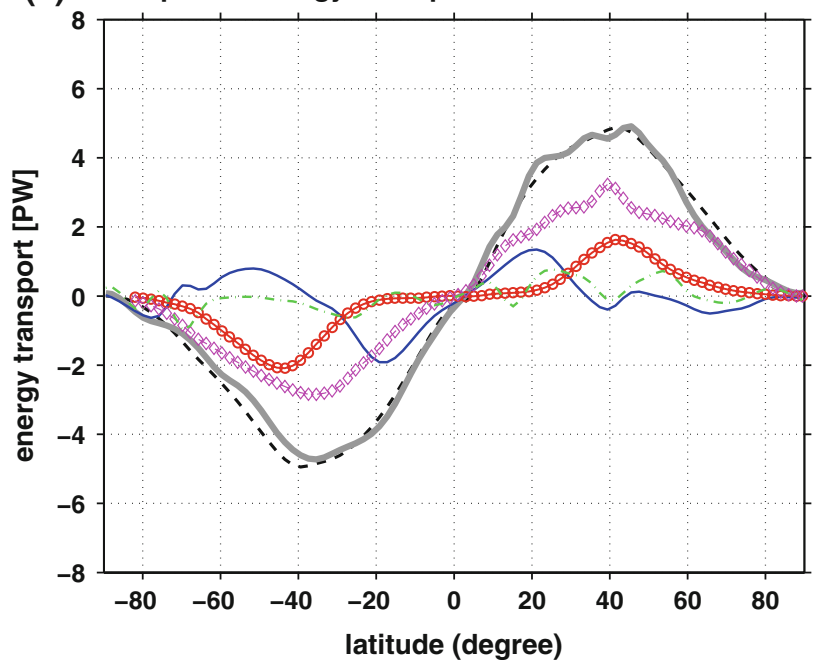

process, the increased atmospheric energy transport, in part, comes from the intensified storm tracks in both seasons in both hemispheres; moreover, the location of the maximum 
(a) trend DJF GFDL

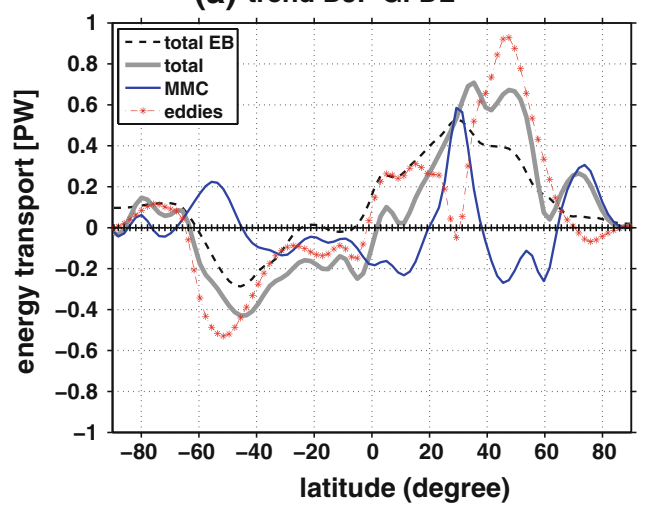

(c) trend JJA GFDL

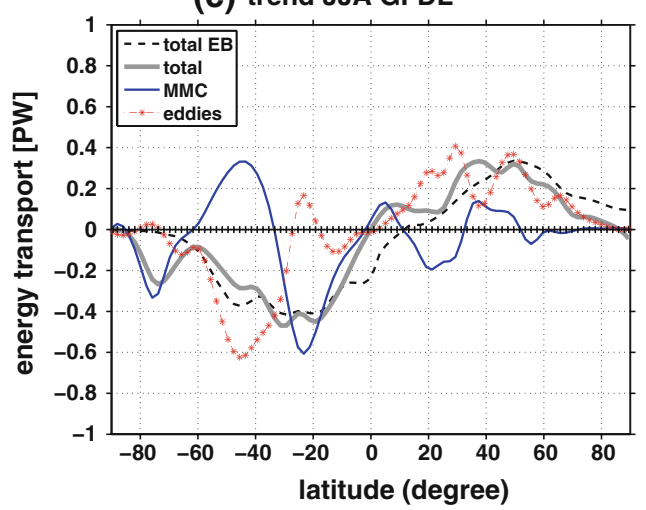

(e) trend annual GFDL

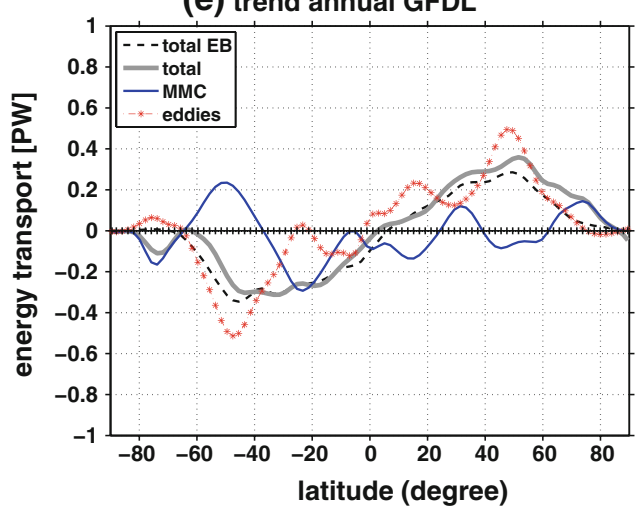

Fig. 12 Global warming trend in zonal mean atmospheric energy transport, i.e. a, c, $\mathbf{e}\left[\overline{T_{A}^{E B}}\right],\left[\overline{T_{A}}\right]$ the energy transport by the mean meridional circulations (MMC) and total eddies (transient and stationary eddies), and $\mathbf{b}, \mathbf{d}, \mathbf{f}$ the energy transport by the storm

energy transport associated with the storm tracks also shifts to the poles in the warming world, which is consistent with the discussions of previous sections. It is also noticed that the intensified stationary waves and low-frequency eddies also have significant contributions to the increased midlatitude energy transport. It is also noticed that the poleward energy transport within the Hadley Cell in DJF in the NH branch decreases in response to global warming because of the increased equatorward transport of atmospheric moisture.

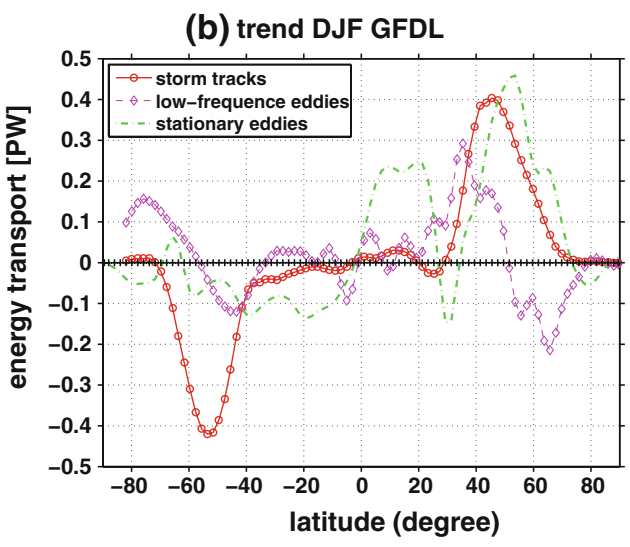

(d) trend JJA GFDL

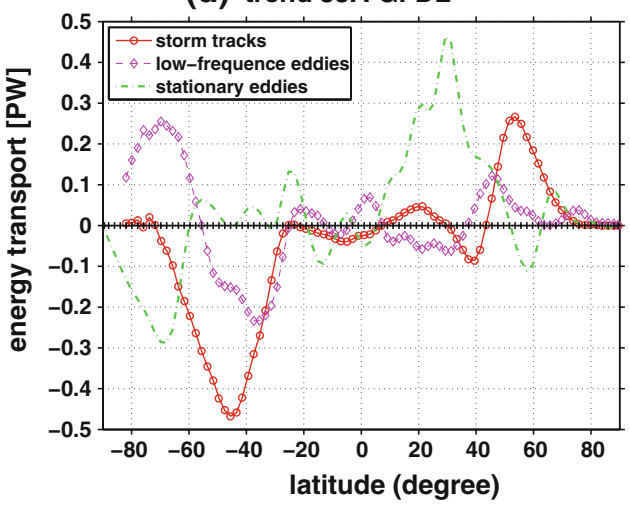

(f) trend annual GFDL

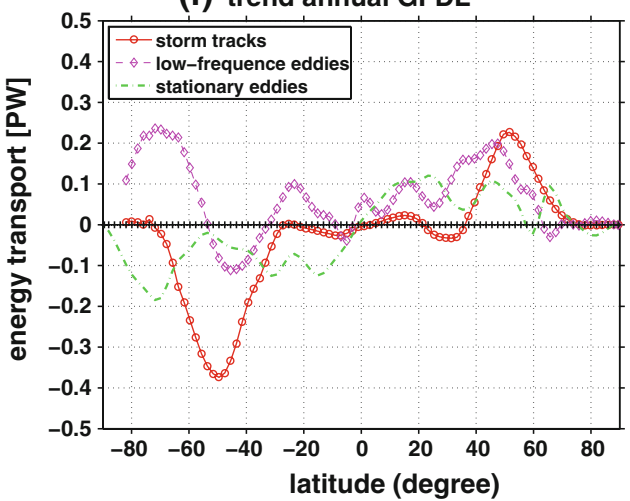

tracks, the low-frequency eddies and the stationary waves, in DJF, JJA and the annual mean, respectively, from the GFDL CM2.1 model simulations. Units are PW

Therefore, this quantitative analysis further confirms the strengthening of the storm tracks in the future climate as an important component of the large-scale general circulation in the atmosphere. The storm tracks intensify in tandem with the atmospheric energy transport in midlatitudes, serving to achieve energy balance in the atmosphere in a warmer climate. Combined with the analysis of baroclinic instability, a possible dynamical mechanism underlying the intensification and the poleward shift of the storm tracks 
Fig. 13 a Climatological and b twenty-first century trend in annual mean meridional total, atmospheric and oceanic heat transport, derived from the energy balance requirement from the GFDL CM2.1 model simulations. Units are PW (a) Annual Energy Transport 1961-2000 GFDL

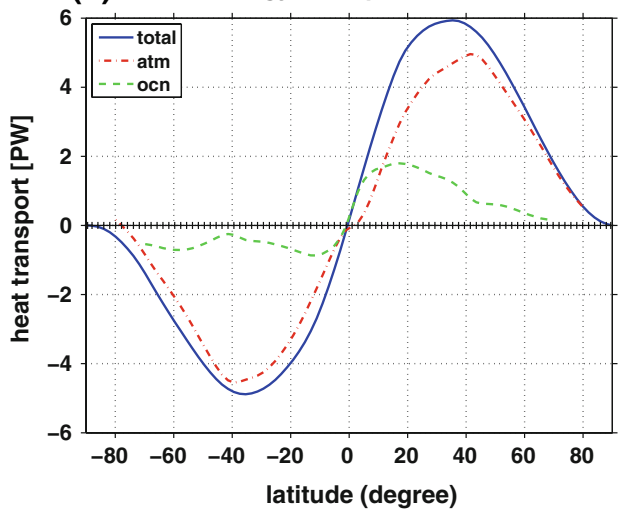

(b) trend annual GFDL

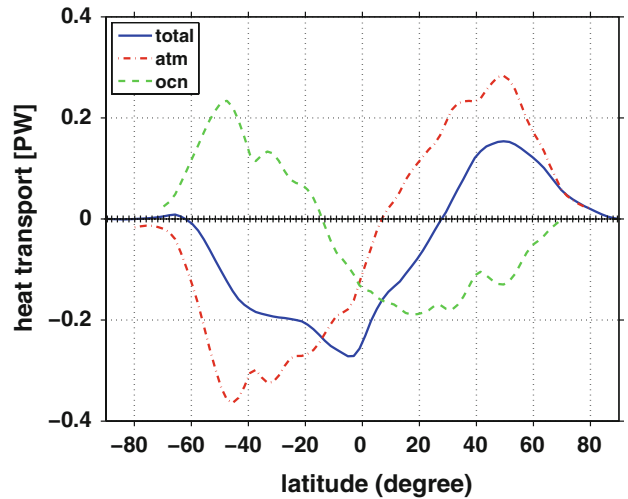

can be summarized as the follows. As climate warms, the planetary and atmospheric energy imbalance enhances which is primarily radiative driven. This provides more available potential energy in the atmosphere causing the midlatitude storm tracks to intensify and to shift towards the poles.

In addition to the thermal structure and the energy transport in the atmosphere, the midlatitude ocean fronts are also important in the formation and development of the storm tracks. Although the oceanic heat transport in the midlatitudes is smaller relative to the atmospheric component (Trenberth and Caron (2001)), the coupling between the atmosphere and the ocean in driving the midlatitude storm tracks has been noticed in both observations and model experiments (see a review by Nakamura et al. (2004)). We have found that the annual mean meridional oceanic heat transport derived from the surface energy balance (with the differential ocean heat storage rate taken into account) reduces in the future projections (Fig. 13; see Appendix). The reduction in oceanic heat transport is, in fact, consistent with the reduction in sea surface temperature contrast and salinity contrast between low and high latitudes, and the weakening of the Meridional Overturning Circulation (MOC) in the North Atlantic and North Pacific (Hazeleger (2005); Meehl et al. (2007)). The detailed analysis of how change in oceanic heat transport impacts the storm tracks in future climate, however, is beyond the scope of this study.

\section{Conclusions}

In this paper we have examined the future projections in the location and amplitude of the storm tracks from the GFDL CM2.1 global coupled climate model simulations, the $A 1 B$ scenario. We have identified a poleward shift, poleward expansion, and intensification on the poleward flank, of storm tracks in the future climate from several band-pass filtered transient eddy statistics. In particular, we have noticed a prominent change in meridional moisture transport associated with the storm tracks, which is important in regulating the hydrological cycle (Seager and Vecchi (2010)); Seager et al. (2010) and atmospheric large-scale general circulation.

The future projections in transient eddy activity and its heat transport well correspond to the changes in baroclinic instability. To first order, the linear baroclinic instability growth rate is in large part determined by the meridional temperature gradients and associated available potential energy. In a warmer climate, the upper troposphere in the tropics warms up more than that at higher latitudes, which implies increasing available potential energy, and thus the linear instability growth rate strengthens and shifts to the poles in the midlatitude upper troposphere. This is consistent with the strengthened transient eddy activity in this region. The zonal mean growth rate decreases in the midlatitude lower troposphere in northern winter because of the significant warming at the high latitude surface, however, the storm tracks intensify on their poleward flank throughout the whole troposphere. This implies that the transient eddy activity is more determined by the baroclinicity in the troposphere as a whole. It is also found that the contributions from the increasing correlation coefficient between eddy motion and eddy energy, the increasing eddy mixing length scale and the increasing eddy velocity overwhelm that from the reduction in mean state gradients and increase transient eddy poleward energy transport in the lower troposphere in northern winter.

As have been found, the enhanced planetary energy imbalance is primarily radiative driven and provides more available potential energy in the atmosphere. The midlatitude transient eddies respond by shifting towards the poles and intensifying on the poleward flank. Analysis of the coupling between the changes in global energy balance and energy transports allows a sequence of cause and effect to be proposed. 
1. Increased carbon dioxide and the associated water vapor feedback cause increased radiative gain in the atmosphere and warming in the tropics and subtropics which strengthens the maximum baroclinicity and shifts the latitude of maximum baroclinicity zone poleward.

2. At the same time, accompanying the increased available atmospheric moisture, the poleward transport of latent heat by transient eddies increases which to a large extent balances the increased meridional gradient in the planetary energy balance.

3. Due to intensified moisture divergence and resulting reduced cloudiness, the subtropical radiative gain increases.

4. At the same time, as a result of increased poleward moisture transport, increased cloudiness is produced in the middle and higher latitudes which reduces the solar radiative gain. Additional radiative loss in these regions results from the increased outgoing terrestrial radiation emitted to space as a result of the surface warming. The feedback from cloud over could further enhance the pole-to-equator energy imbalance leading to more intensified poleward energy transport by transient eddies.

5. Over the Southern Ocean, the ocean heat uptake increases as a consequence of increased greenhouse gases which results in reduced surface fluxes from the ocean. This atmosphere-ocean coupling enhances the energy imbalance in the atmosphere leading to further intensified transient eddy activity in the Southern Hemisphere.

Our main objective in this paper is to understand the dynamical mechanisms for the storm track response in a warmer climate, both in terms of the change in baroclinic instability and the change in global energy budget in the atmosphere. The current study focuses on the GFDL CM2.1 global coupled climate model simulations. Further works include the extension to other IPCC models with available daily data to confirm the connections between eddy response and global atmospheric energy imbalance. Simple atmospheric model experiments with doubled carbon dioxide will be used to confirm and refine the proposed causality sequence of the transient eddy response in a warmer climate. In addition, how the transient eddy wave structures change under global warming and their connections to the poleward energy transfer will be investigated in future work.

Acknowledgments The authors would like to thank two anonymous reviewers for their insightful comments which lead to significant improvement of the paper. We also thank Nili Harnik for helpful discussions. This work was supported by NOAA CPPA Program and by NSF grant ATM-0543256. YW was also supported by NASA
Headquarters under the NASA Earth and Space Science Fellowship Program -Grant NNX08AU80H.

\section{Appendix}

Change in oceanic heat transport

The meridional oceanic heat transport can be derived from the surface energy balance and is written as

$S_{o}=R_{\text {surface }}-S H-L H-\nabla \cdot F_{o}$

where $S_{o}$ denotes the rate of ocean heat storage, $R_{\text {surface }}$ is the net downward radiative flux at the surface, $S H$ and $L H$ are the surface upward sensible and latent heat fluxes, and $F_{o}$ denotes the oceanic heat transport. The difference from the derivation in atmospheric energy transport is that the ocean heat storage can't be neglected in the long term as climate warms. The heat storage rate is defined as the oceanic potential temperature difference between years 1961-2000 and years 2081-2100 integrated over the ocean depth, multiplying by the sea water density and heat capacity, divided by the time period of 110 years. It is quite uniformly distributed over latitude and is calculated to be about $1.5 \mathrm{~W} / \mathrm{m}^{2}$ on global average (consistent with Russell et al. (2006a)). Increased heat storage is relatively larger over the Southern Ocean and smaller over the North Atlantic region (not shown). Figure 13a shows the climatological meridional total, atmospheric and oceanic energy transport derived from the energy balance requirement. Taking the differential ocean heat storage rate into account, Fig. 13b shows the change in total, atmospheric and oceanic heat transport in the future climate. It is noted that the oceanic heat transport decreases almost everywhere whereas the atmospheric heat transport increases. Held and Soden (2006) pointed out that the reduction in meridional ocean heat transport serves as a compensation for the increased poleward latent heat transport in the atmosphere.

\section{References}

Bengtsson L, Hodges KI, Roeckner E (2006) Storm tracks and climate change. J Clim 19:3518-3543

Blackmon ML (1976) A climatological spectral study of the $500 \mathrm{mb}$ geopotential height of the Northern Hemisphere. J Atmos Sci 33:1607-1623

Carissimo BC, Oort AH, Haar THV (1985) Estimating the meridional energy transports in the atmosphere and ocean. J Phys Oceanogr 15:82-91

Chang EK (1993) Downstream development of baroclinic waves as inferred from regression analysis. J Atmos Sci 50:2038-2053

Chang EKM, Lee S, Swanson KL (2002) Storm track dynamics. J Clim 15:2163-2183 
Charney JG (1947) The dynamics of long waves in a baroclinic westerly current. J Meteorol 4:135-162

Chen G, Lu J, Frierson DM (2008) Phase speed spectra and the latitude of surface westerlies: interannual variability and global warming trend. J Clim 21:5942-5959

Delworth TL et al (2006) GFDL's CM2 global coupled climate models. Part I. Formulation and simulation characteristics. J Clim 19:643-674

Eady ET (1949) Long waves and cyclone waves. Tellus 1:33-52

Emanuel KA, Fantini M, Thorpe AJ (1987) Baroclinic instability in an environment of small stability to slantwise moist convection. Part I. Two-dimensional models. J Atmos Sci 44:1559-1573

Frierson DMW, Held IM, Zurita-Gotor P (2006) A gray-radiation aquaplanet moist GCM. Part I. Static stability and eddy scale. J Atmos Sci 63:2548-2566

Frierson DMW, Held IM, Zurita-Gotor P (2007) A gray-radiation aquaplanet moist GCM. Part II. Energy transports in altered climates. J Atmos Sci 64:1680-1693

Fyfe JC (2003) Extratropical Southern Hemisphere cyclones: Harbingers of climate change. J Clim 16:2802-2805

Gastineau G, Soden BJ (2009) Model projected changes of extreme wind events in response to global warming. Geophys Res Lett 36:L10 810. doi:10.1029/2009GL037500

Geng Q, Sugi M, (2003) Possible change of extratropical cyclone activity due to enhanced greenhouse gases and sulfate aerosolsstudy with a high-resolution AGCM. J Clim 16:2262-2274

Green JSA (1970) Transfer properties of the large-scale eddies and the general circulation of the atmosphere. Quart J Roy Meteorol Soc 96:157-185

Gregory JM, Mitchell JFB, Brady AJ (1996) Summer drought in Northern Midlatitudes in a time-dependent $\mathrm{CO}_{2}$ climate experiment. J Clim 10:662-686

Hall NMJ, Hoskins BJ, Valdes PJ, Senior CA (1994) Storm tracks in a high-resolution GCM with doubled carbon dioxide. Quart J Roy Meteorol Soc 120:1209-1230

Hansen JE, Lacis A, Rind D, Russell G, Stone P, Fung I, Ruedy R, Lerner J (1984) Climate sensitivity: analysis of feedback mechanisms. In: Hansen JE, Takahashi T (eds) Climate processes and climate sensitivity, AGU Geophysical Monograph 29, Maurice Ewing vol 5. American Geophysical Union, pp 130-163

Harnik N, Lindzen RS (1997) The effect of basic-state potential vorticity gradients on the growth of baroclinic waves and the height of the tropopause. J Atmos Sci 55:344-360

Hazeleger W, (2005) Can global warming affect tropical ocean heat transport?. Geophys Res Lett 32:L22 701. doi:10.1029/2005 GL023450

Held IM (1993) Large-scale dynamics and global warming. Bull Am Meteorol Soc 74:228-241

Held IM, O'Brien E (1992) Quasigeostrophic turbulence in a threelayer model: effects of vertical structure in the mean shear. J Atmos Sci 49:1861-1870

Held IM, Soden BJ (2006) Robust response of the hydrological cycle to global warming. J Clim 19:5686-5699

Hoskins BJ, Valdes PJ (1990) On the existence of storm-tracks. J Atmos Sci 47:1854-1864

Kalnay E et al (1996) The NCEP/NCAR 40-year reanalysis project. Bull Am Meteorol Soc 77:437-471

Kunz T (2008) The role of breaking synoptic scale Rossby waves for the North Atlantic oscillation and its coupling with the stratosphere. Ph.D. thesis, der Universitat Hamburg

Lambert SJ (1995) The effect of enhanced greenhouse warming on winter cyclone frequencies and strengths. J Clim 8:1447-1452

Lambert SJ, Fyfe JC (2006) Changes in winter cyclones frequencies and strengths simulated in enhanced greenhouse warming experiments: results from the models participating in the IPCC diagnostic exercise. Clim Dyn 26:713-728
Lapeyre G, Held IM (2004) The role of moisture in the dynamics and energetics of turbulent baroclinic eddies. J Atmos Sci 61:16931710

Levitus S, Antonov JI, Wang J, Delworth TL, Dixon KW, Broccoli AJ (2001) Anthropogenic warming of earth's climate system. Sci 292:267-270

Lin SJ (2004) A vertically Lagrangian finite-volume dynamical core for global models. Mon Wea Rev 132: 2293-2307

Lindzen RS, Farrell BF (1980) A simple approximation result for maximum growth rate of baroclinic instabilities. J Atmos Sci 37:1648-1654

Lorenz EN (1955) Available potential energy and the maintenance of the general circulation. Tellus 7:157-167

Lorenz DJ, DeWeaver ET (2007) Tropopause height and zonal wind response to global warming in the IPCC scenario integrations. J Geophys Res 112:D10 119. doi:10.1029/2006JD008087

Lu J, Vecchi GA, Reichler T (2007) Expansion of the Hadley cell under global warming. Geophys Res Lett 34:L06 805. doi: 10.1029/2006GL028443

Lunkeit F, Fraedrich K, Bauer SE (1998) Storm tracks in a warmer climate: sensitivity studies with a simplified global circulation model. Clim Dyn 14:813-826

McCabe GJ, Clark MP, Serreze MC (2001) Trends in Northern Hemisphere surface cyclone frequency and intensity. J Clim 14:2763-2768

Meehl GA et al (2007) Global climate projections. In: Solomon S, Qin D, Manning M, Chen Z, Marquis M, Averyt KB, Tignor M, Miller HL (eds) Climate Change 2007: The Physical Science Basis. Contribution of Working Group I to the Fourth Assessment Report of the Intergovernmental Panel on Climate Change, Cambridge University Press, Chap. 10, pp 747-846

Nakamura H, Sampe T, Tanimoto Y, Shimpo A (2004) Observed associations among storm tracks, jet streams and midlatitude oceanic fronts, earth's climate: the ocean-atmosphere interaction. In: Wang C, Xie S-P, Carton JA (eds) Geophys Monogr, 147, American Geophysical Union, Washington, pp 329-346

O'Gorman PA, Schneider T (2008) Energy of midlatitude transient eddies in idealized simulations of changed climates. J Clim 21:5797-5806

Pavan V (1995) Sensitivity of a multi-layer quasi-geostrophic $\beta$-channel to the vertical structure of the equilibrium meridional temperature gradient. Quart J Roy Meteorol Soc 122:55-72

Pavan V, Hall N, Valdes P, Blackburn M (1999) The importance of moisture distribution for the growth and energetics of midlatitude systems. Ann Geophys 17:242-256

Randel WJ, Held IM (1991) Phase speed spectra of transient eddy fluxes and critical layer absorption. J Atmos Sci 48:688-697

Russell JL, Dixon KW, Gnanadesikan A, Stouffer RJ, Toggweiler JR (2006a) The Southern Hemisphere westerlies in a warming world: propping open the door to the deep ocean. J Clim 19:6382-6390

Russell JL, Souffer RJ, Dixon KW (2006b) Intercomparison of the Southern Ocean circulations in the IPCC coupled model control simulations. J Clim 19:4560-4575

Seager R, Murtugudde R, Clement AC, Herweijer C (2003) Why is there an evaporation minimum at the Equator. J Clim 16:37923801

Seager R, et al (2007) Model projections of an imminent transition to a more arid climate in southwestern North America. Science 316: 1181-1184

Seager R, Naik N, Vecchi G (2010) Thermodynamic and dynamic causes of large-scale changes in the hydrological cycle in response to global warming. J Clim (submitted)

Seager R. Vecchi G (2010) Global warming and the 21st century climate of southwestern North America. Proc Natl Acad Sci USA (submitted) 
Son S-W et al (2008) The impact of stratospheric ozone recovery on the Southern Hemisphere westerly jet. Science 320: 1486-1489

Son S-W, Tandon NF, Polvani LM, Waugh DW (2009) Ozone hole and Southern Hemisphere climate change. Geophys Res Lett 36:L15 705. doi:10.1029/2009GL038671

Stephenson DB, Held IM, (1993) GCM response of northern winter stationary waves and storm tracks to increasing amounts of carbon dioxide. J Clim 6:1859-1870

Trenberth KE, Caron JM (2001) Estimates of meridional atmosphere and ocean heat transports. J Clim 14:3433-3443

Trenberth KE, Stepaniak DP (2003) Seamless poleward atmospheric energy transports and implications for the Hadley circulation. J Clim 16:3705-3721
Trenberth KE, Caron JM, Stepaniak DP (2001) The atmospheric energy budget and implications for surface fluxes and ocean heat transports. Clim Dyn 17:259-276

Trenberth KE, Fasullo JT, Kiehl J (2009) Earth's global energy budget. Bull Am Meteorol Soc 90:311-323

Vallis GK, (2006) Atmospheric and oceanic fluid dynamics. Cambridge University Press, Cambridge, p 745

Wittman MAH, Charlton AJ, Polvani LM (2007) The effect of lower stratospheric shear on baroclinic instability. J Atmos Sci 64:479_ 496

Yin $\mathrm{H}$ (2005) A consistent poleward shift of the storm tracks in simulations of 21 st century climate. Geophys Res Lett 32: L18 701. doi:10.1029/2005GL023684 